\title{
Jogando o bebê junto com a água do banho: Wittgenstein, Goodstein e o cálculo equacional
}

Mathieu Marion

Université du Québec à Montréal

marion.mathieu@uqam.ca

resumo Reuben Louis Goodstein (1912-1985) foi aluno de Wittgenstein em Cambridge de 1931 a 1934. Neste artigo, faço uma breve descrição de seu trabalho na lógica matemática, no qual se percebe a influência das idéias de Wittgenstein, inclusive a substituição, em seu cálculo equacional, da indução matemática por uma regra de unicidade de uma função definida por uma função recursiva. Esse último aspecto se encontra no Big Typescript de Wittgenstein. Também mostro que as idéias fundamentais do cálculo equacional podem ser encontradas não apenas no período intermediário, mas, in nuce, nas observações sobre matemática do Tractatus Logico-philosophicus. A partir disso, procuro desenvolver um argumento contra uma leitura corrente daquele livro, o assim chamado “Novo Wittgenstein". Outra conexão entre Goodstein e Wittgenstein se encontra na rejeição da teoria da quantificação; na parte final do artigo, recorro às observações críticas de Goodstein sobre a Lei do Terceiro Excluído (que também incluem uma crítica a Brouwer e à sua rejeição "pela metade" dessa lei) para lançar luz sobre as observações do próprio Wittgenstein a esse respeito.

palavras-chave Wittgenstein; Goodstein; cálculo equacional; “Novo Wittgenstein"; indução matemática; regra de unicidade

Man kann nicht eine Rechnung als den Beweis eines Satzes bestimmen. Ludwig Wittgenstein 


\section{Quem foi Goodstein, e por que os "wittgensteinianos" devem se importar com isso?}

Dentre os matemáticos cuja principal área de interesse é a lógica matemática, Reuben Louis Goodstein (1912-1985) foi o primeiro a ter uma cátedra numa universidade britânica, como professor da Universidade de Leicester desde 1948 até sua aposentadoria, em 1977. ${ }^{1}$ Ele estudou na Universidade de Cambridge a partir de 1931, tendo obtido grau máximo nas duas etapas do Mathematical Tripos ${ }^{2}$ (1931 e 1932), e um M.Sc. ${ }^{3}$ em 1935. De 1933 até 1935, Goodstein estudou os números transfinitos sob a supervisão de J. E. Littlewood. Tais estudos estão provavelmente na origem de seus trabalhos a respeito do "teorema ordinal restrito" (GOODSTEIN, 1944, 1947), pelos quais é reconhecido até hoje. O principal resultado que ele obteve nesta área ficou conhecido, aliás, como "Teorema de Goodstein". ${ }^{4}$ Esse teorema é o análogo aritmético do fato de todas as sequências estritamente decrescentes de ordinais transfinitos serem finitas, mas sua importância só foi reconhecida quando Laurence Kirby e Jeff Paris mostraram que ele fornece um enunciado da teoria dos números que não pode ser provado na aritmética de Peano de primeira ordem, oferecendo, portanto, um equivalente matemático do teorema da incompletude de Gödel (KIRBY, L. \& PARIS, J., 1982). ${ }^{5}$

Em Cambridge, Goodstein também assistiu às aulas dadas por Ludwig Wittgenstein de 1931 até 1934, tendo se tornado um de seus discípulos favoritos. Na verdade, quando o curso de "Filosofia para Matemáticos", oferecido em 1933, ficou superlotado, Wittgenstein cancelou-o após algumas semanas, ditando no seu lugar aquilo que ficou conhecido como o "Livro Azul" para um seleto grupo que incluía, além de Goodstein, Alice Ambrose, Margaret Masterman, e dois estudantes de matemática, o geômetra H. S. M. Coxeter e Francis Skinner. ${ }^{6}$ É bastante surpreendente que, com exceção de umas poucas notas curtas publicadas na Mathematical Gazette da Mathematical Association, o primeiro artigo de peso de Goodstein tenha sido de cunho filosófico: "Mathematical Systems", publicado na revista Mind em 1939. Goodstein sentiu-se obrigado a declarar, logo no início, que

[...] no que diz respeito às ideias críticas [deste artigo], sinto-me em dívida, numa medida muito maior do que seria possível evidenciar por 
meio de referências e agradecimentos, para com meu ex professor, o Dr. L. Wittgenstein (GOODSTEIN, 1939, p. 58). ${ }^{7}$

Em 1951 (portanto, enquanto Wittgenstein ainda estava vivo), Goodstein disse o seguinte no prefácio de Constructive Formalism:

Dentre os muitos amigos que me ajudaram, encorajaram e inspiraram na elaboração desta obra, devo mencionar, antes e acima de qualquer outra pessoa, Ludwig Wittgenstein; devo muitíssimo a suas aulas em Cambridge entre 1931 e 1934, bem como às inúmeras conversas que tive o privilégio de ter com ele. Apenas nestes anos mais recentes pude finalmente compreender o quanto ele me ensinou. (GOODSTEIN, 1951 , p. 10)

Conforme vem indicado nesta última observação, as ideias de Wittgenstein não tiveram inicialmente muito impacto sobre a obra matemática de Goodstein, mas seus trabalhos no pós-guerra evidenciam uma influência indiscutível ${ }^{8}$, e ele continuará elogiando Wittgenstein até bem mais tarde em sua carreira, como se pode ver, por exemplo, em "Wittgenstein's Philosophy of Mathematics" (GOODSTEIN, 1972). . Em 1945, Goodstein introduziu um "cálculo equacional” em seu artigo "Function Theory in an Axiom-Free Equation Calculus" (GOODSTEIN, 1945). Haskell Curry havia apresentado um cálculo equacional alguns anos antes (CURRY, 1941), ${ }^{10}$ sendo que uma das maiores diferenças entre ambos era a substituição, no cálculo equacional de Goodstein, da indução matemática por uma regra de unicidade para uma função definida por uma função recursiva. ${ }^{11}$ Tomada como esquema axiomático, a indução pode ser expressa do seguinte modo (onde $\mathrm{S}$ é a função sucessor):

(I) $\quad(F(0) \&(\forall \mathrm{x} F(x) \rightarrow F(S x))) \rightarrow \forall \mathrm{x} F(x)$

Já a "regra de unicidade" pode ser escrita do seguinte modo:

$$
F(0)=G(0) \quad F(\mathrm{~S}(x))=H(x, F(x)) \quad G(\mathrm{~S}(x))=H(x, \mathrm{~S}(x))
$$

(U)

$$
F(x)=G(x)
$$

(onde $\mathrm{F}, \mathrm{G}$ e $\mathrm{H}$ são funções recursivas primitivas, e $\mathrm{S}$ é novamente a função sucessor). 
Numa nota de rodapé a seu artigo de 1945 (GOODSTEIN, 1945, p. 407), Goodstein atribuiu esta substituição a Wittgenstein. ${ }^{12}$ Ele volta a discutir essa atribuição de modo mais detalhado num artigo que escreveu muitos anos mais tarde, "Wittgenstein's Philosophy of Mathematics" (GOODSTEIN, 1972, p. 280-282). Na verdade, pode-se encontrar a ideia claramente enunciada na seção 127 do Big Typescript, de 1933 (WITTGENSTEIN, 2005, p. 445; daqui em diante, BT). Como esse material não estava acessível a todos até a publicação da versão academicamente inacurada de Rhees, a Philosophical Grammar (WITTGENSTEIN, 1974, p. 397; daqui em diante, PG), Goodstein deve ter mencionado Wittgenstein em 1945 baseado apenas em sua memória de aulas ou discussões, ou ainda por ter tido acesso ao Big Typescript, muito provavelmente antes de 1935. (Não se sabe muito bem se eles tiveram muito contato depois que Goodstein deixou Cambridge.) A ideia subjacente à regra da unicidade e as razões pelas quais Wittgenstein foi levado a ela serão explicadas mais abaixo. Minhas observações, no entanto, não ficarão restritas a este tópico. Tentarei mostrar que as ideias subjacentes ao cálculo equacional já estão presentes in nuce no Tractatus Logico-Philosophicus, e que Wittgenstein continuou a elaborá-las durante o assim chamado "período intermediário" (1929-1935), precisamente na época em que Goodstein foi seu aluno.

Tendo por base o seu cálculo equacional, Goodstein desenvolveu, na tradição de Kronecker e Skolem, ${ }^{13}$ um sistema de aritmética recursiva primitiva no livro Recursive Number Theory (GOODSTEIN, 1957a), e mais tarde formulou também um sistema de análise primitiva recursiva, em Recursive Analysis (GOODSTEIN, 1961), no qual os quantificadores existenciais que ocorrem nas definições usuais são substituídos por funções primitivas recursivas. Numa série de artigos, Goodstein apresentou diversos resultados, tais como a transcendência recursiva de $\pi$ (GOODSTEIN \& HOOLEY, 1960) ou a reformulação da segunda prova dada por Gauss do teorema fundamental da álgebra (GOODSTEIN, 1969), mostrando o quanto é possível fazer, com engenho, no interior deste cenário que pode, à primeira vista, parecer excessivamente estreito. $\mathrm{O}$ comentário lacônico feito por H. E. Rose em seu obituário resume bem esta reclamação típica: ${ }^{14}$

A principal crítica feita a esta abordagem é que vastas áreas da matemática ficam completamente ignoradas. (ROSE, 1988, p. 163) 
É bem verdade que Goodstein raramente lidou com a recursão múltipla, e que ele jamais chegou a fazer uma investigação satisfatória da hierarquia sub-recursiva. ${ }^{15}$ É também verdade que tanto a aritmética clássica quanto a intuicionista vão além da aritmética recursiva de Goodstein. Seja como for, o desenvolvimento da matemática reversa a partir dos anos 80,16 ou, para mencionar outra obra produzida na mesma década, a aritmética predicativa de Edward Nelson (NELSON, 1986) acabaram mostrando o quanto são infundados os preconceitos neste campo. Este, porém, certamente não é o lugar adequado para avaliarmos a força fundacional da perspectiva recursiva primitiva de Goodstein, no âmbito, p. ex., da matemática reversa, e tampouco é minha intenção discutir neste artigo assuntos pertinentes aos fundamentos da matemática. Estou interessado na influência de Wittgenstein sobre Goodstein e, acima de tudo, na interpretação da filosofia de Wittgenstein. ${ }^{17} \mathrm{Na}$ filosofia da matemática, temos sempre a tendência de avaliar as ideias em termos de sua força fundacional. No entanto, se pusermos o foco apenas sobre esse aspecto, não seremos capazes de nos debruçar sobre os interesses específicos de Wittgenstein, dos quais podem resultar ideias novas que não sejam diretamente relevantes para os "fundamentos". Por exemplo, alguém poderia objetar que a indução matemática e a regra de unicidade são equivalentes (ainda que nem sempre), e perguntar - para que se preocupar com isso? Pessoas que lidam com teoria das categorias, por exemplo, se permitiriam discordar. ${ }^{18}$

Muito embora as observações de Goodstein a respeito de Wittgenstein, atribuindo a ele a substituição da indução pela unicidade, estivessem aí para quem quisesse lê-las, e as observações feitas pelo próprio Wittgenstein tenham ficado disponíveis para o grande público desde a publicação da Gramática Filosófica na década de 70, creio que fui o primeiro a chamar a atenção para elas (MARION, 1995a, p. 155-156) (MARION, 1998, p. 107-109). A excitação gerada pelo assim chamado "Novo Wittgenstein" (CRARY \& READ, 2000) ${ }^{19}$ teve efeitos deletérios sobre o estudo das observações de Wittgenstein a respeito da matemática. Pouquíssimos estudiosos de Wittgenstein pensaram que estas observações merecessem mais do que um exame superficial. Elas eram facilmente deixadas de lado, e imaginava-se todo tipo de desculpa para não se pôr os olhos sobre elas. Cora Diamond e congêneres simplesmente não foram exceções a essa regra. Num apêndice a seu artigo "Throwing Away the Ladder", funda- 
mental para este tipo de abordagem, ela se opõe à ideia de que alguém possa estudar as observações de Wittgenstein sobre a matemática independentemente de suas observações sobre a natureza da filosofia, sugerindo, pelo contrário, que deveríamos entender as observações sobre a matemática conjuntamente com uma concepção da filosofia "radicalmente incompatível com a filosofia-enquanto-doutrina” (DIAMOND, 1991, p. 202-203).

Esta atitude bastante disseminada, no entanto, tinha por resultado quase exclusivo uma série de alegações superficiais e pouco esclarecedoras, segundo as quais Wittgenstein não poderia ter defendido este ou aquele "ismo" sobre a matemática, pois isto seria incompatível com sua perspectiva radical contra "teses" ou "teorias" na filosofia. Dificilmente poderíamos chamar isto tudo de interpretação conjunta, e isso se mostra ainda mais problemático quando levamos a sério o fato de que as observações sobre a matemática constituem quase metade de sua produção escrita. Como sempre, essas observações são propositalmente ignoradas.

Não estaremos fazendo uma caricatura se descrevermos o "Novo Wittgenstein" como o ponto de vista segundo o qual só a "moldura" do Tractatus (isto é, as sentenças a seguir) faz sentido, enquanto o restante do livro não passa de contrassenso puro e simples:

Prefácio - O significado total do livro poderia de algum modo ser resumido assim: $\mathrm{O}$ que pode ser dito pode ser dito claramente; e sobre aquilo que não se pode falar deve-se calar. O livro traçará, portanto, um limite ao pensamento. Ou, melhor - não ao pensamento, mas à expressão de pensamentos; pois, para traçar um limite ao pensamento, deveríamos ser capazes de pensar em ambos os lados deste limite (deveríamos, portanto, ser capazes de pensar o que não pode ser pensado). O limite só pode, portanto, ser traçado na linguagem, e aquilo que está do outro lado do limite será simplesmente contrassenso. $[\ldots]$

6.54 - Minhas proposições são esclarecedoras deste modo: aquele que me entende acaba reconhecendo-as como contrassensos, tão logo tiver galgado através delas, sobre elas, para além delas. (Ele deve, por assim dizer, jogar fora a escada, após ter subido por ela.)

[...]

7 - Sobre o que não se pode falar, deve-se calar. ${ }^{20}$ 
Como não poderia deixar de ser, a empreitada como um todo irá se resumir numa série de casuísmos a respeito destas sentenças, ou seja, muita falação a respeito de "como ler o Tractatus" num contexto em que nossa agenda externa ao ler o Tractatus transformou-se sub-repticiamente no único ponto em pauta. Esta atitude, mais uma vez, teve efeitos nocivos sobre o estudo daquilo que Wittgenstein disse a respeito da matemática, já que as observações sobre a matemática inserem-se inequivocamente no interior da moldura do livro: elas devem, portanto, ser vistas como meros constrassensos. Estamos diante de algo equivalente a um $u k a z^{21}$ no estudo daquelas observações.

A má vontade no enfrentamento das observações de Wittgenstein sobre a matemática estende-se, é claro, às pouco conhecidas conexões com Goodstein. Só conheço um único outro estudo a respeito, feito, não por um filósofo, mas por um lógico (OKADA, 2007). O que era de esperar, tendo-se em vista o peso dos preconceitos no interior da comunidade filosófica. Em minhas considerações finais, voltarei a estes temas, tirando algumas conclusões negativas a respeito do "Novo Wittgenstein". Minha tese será a seguinte: o uso feito por Goodstein de ideias que supostamente seriam de Wittgenstein permite-nos melhorar nosso entendimento do ponto de vista assumido pelo próprio Wittgenstein. Este entendimento melhorado, entretanto, choca-se com o "Novo Wittgenstein", que se traduz, neste caso, na alegação de que um cálculo equacional é uma tentativa impossível de teorizar sobre "aquilo que é mostrado". O próprio fato de Wittgenstein ter continuado, ao longo dos anos 30, a pensar profundamente a respeito de temas como a substituição da indução pela unicidade é por si só uma indicação tão clara quanto possível de que essa alegação não pode ser verdadeira.

\section{Sendo Ludwig Wittgenstein}

Os debates gerados pelo "Novo Wittgenstein" giram em torno de nosso entendimento da noção wittgensteiniana de "contrassenso" (Unsinn) no Tractatus. Em 6.54, Wittgenstein usou, como vimos, a metáfora da escada pela qual temos de subir, mas que devemos jogar fora assim que chegarmos ao topo. O que nos resta, porém, depois que nos livramos dela? 
Segundo aquilo que parecia ser a "ortodoxia" neste assunto, ficamos acenando na direção de certo conteúdo inefável, que seria per impossibile verdadeiro, caso fosse expresso na linguagem. O problema é que qualquer tentativa de expressar esse conteúdo na linguagem acabaria inevitavelmente gerando contrassensos. Tentarei mostrar mais adiante que algo muito semelhante a isto é verdadeiro da matemática, onde as equações mostram que o lado esquerdo transforma-se no lado direito, enquanto o correspondente linguístico (usualmente um enunciado quantificado do tipo "para todo...") é uma tentativa de dizer aquilo que a equação mostra, e está condenado a ser um contrassenso. No entanto, somos avisados de que este não é um entendimento correto do Tractatus em geral, ou das observações sobre a matemática em particular:

$\mathrm{O}$ que exatamente deveria permanecer $[\ldots]$ depois que jogamos fora a escada? Devemos manter a idéia de que há esta ou aquela coisa na realidade para a qual nós acenamos, de tal modo que isso, aquilo para que acenamos, está lá, mas não pode ser expresso em palavras?

Isso é o que eu chamo de fugir da raia. Não fugir da raia, neste caso, é admitir o seguinte: jogar fora a escada significa, entre outras coisas, jogar fora a tentativa de levar a sério a linguagem que se refere a "aspectos da realidade". Ler o próprio Wittgenstein como alguém que não foge da raia é afirmar que ele não achava que existem aspectos da realidade que não podem ser postos em palavras, mas se mostram. Ele achava que esse modo de falar pode ser útil, ou mesmo essencial por algum tempo, mas no final das contas deve ser abandonado, e honestamente considerado como um contrassenso genuíno, um contrassenso puro e simples, que não pode ser pensado como algo que corresponderia em última instância a uma verdade inefável. (DIAMOND, 1991, p. 181)

No final das contas, portanto, somos deixados apenas com a constatação de que toda filosofia tem por resultado o contrassenso puro e simples. A chave para esta leitura é a tese de que Wittgenstein opera o tempo todo com uma única categoria de contrassenso, de tal modo que uma sentença como "Die Welt is alles, was der Fall ist" é um contrassenso exatamente como "piggly wiggle tiggle", para usar o exemplo dado pela própria Diamond (DIAMOND, 2000, p. 158). Eis aqui algumas passagens extraídas de um artigo mais recente: 22 
Nós, enquanto leitores, deveríamos pensar bem a respeito da observação de Wittgenstein segundo a qual, do outro lado do limite, o que existe é pura e simplesmente contrassenso. Será que isso deve nos fazer rejeitar a imagem que tínhamos de duas categorias de coisas - as que podemos atingir por meio de palavras, e as que estão fora do alcance delas? [...] sua afirmação de que aquilo que está do outro lado do limite é simplesmente contrassenso parece ter a intenção de afastar exatamente a idéia de que algumas de nossas sentenças são contrassensos, mas apesar disso conseguem gesticular na direção das coisas que não podem ser postas em palavras. (DIAMOND, 2000, p. 150) Creio que o Tractatus advoga aquilo que poderíamos chamar de uma visão austera do contrassenso. Contrassenso é contrassenso. Não há diferentes tipos de contrassenso [...] e, portanto, não existem proposições com o auxílio das quais nós poderíamos gesticular, ainda que de forma canhestra, na direção de verdades indizíveis.

(DIAMOND, 2000, p. 153)

[...] não existem contrassensos sentenciais que estariam, por assim dizer, mais próximos de serem verdadeiros do que outros. Estou rejeitando algo que foi claramente expresso por Elizabeth Anscombe: a ideia de que existiriam algumas sentenças que são contrassensos, mas que diriam algo verdadeiro, caso aquilo que elas estão tentando dizer pudesse ser dito. (DIAMOND, 2000, p. 158)

Uma das consequências desta leitura "austera" ou "resoluta"23 é que as proposições do Tractatus transformam-se todas em "contrassensos reais, puros e simples contrassensos". Não existe mais a categoria dos contrassensos sofisticados que gesticulariam na direção de algumas verdades inefáveis, pois tais verdades não existem. Pelo contrário, o objetivo do livro seria solapar qualquer tentativa de capturar estas verdades, ainda que fosse por meio de um discurso indireto, tentando mostrar que toda essa parafernália não passa de um amontoado de palavras sem sentido. Isso quer dizer que poderíamos substituir tudo aquilo que está no interior da moldura por, digamos, um texto como Jabberwock ${ }^{24}$, e então republicar o Tractatus? Não é meu objetivo aqui examinar a fundo as dificuldades deste tipo de leitura. Desejo apenas pôr o foco sobre uma delas, que foi desde cedo apontada por P. M. S. Hacker. Ela envolve a falta de cuidado de Diamond na citação que 


\section{4}

fizemos logo acima, quando ela afirma que, para Wittgenstein, há um "modo de falar" que "pode ser útil, ou mesmo essencial por algum tempo", mas que "no final das contas deve ser abandonado, e honestamente considerado como um contrassenso genuíno". Uma sentença não pode fazer sentido num primeiro momento, e ser um contrassenso depois. Caso se trate de um contrassenso puro e simples, então será isso sempre, de modo patente e imediato. Pretender que certos amontoados de palavras sem sentido são imediatamente reconhecidos enquanto tais, ao passo que outros amontoados do mesmo tipo conseguem enganar os filósofos é reintroduzir uma distinção ali onde se supunha não haver distinção alguma. Para começar, se se trata de um "contrassenso genuíno", como é que este "modo de falar" irá fazer o seu trabalho? Como é que subimos degraus com a ajuda de contrassensos como "Die Welt is alles, was der Fall ist", se isto é um contrassenso tão completo quando "piggly wiggle tiggle"? Será que o Tractatus funciona de modo causal, como se fosse uma pancada na cabeça?25 Eis como Hacker se expressa a este respeito:

$[\ldots]$ se alguns casos de contrassenso (transicional) nos levam a compreender que outros casos de contrassenso são, na verdade, casos de contrassenso puro e simples, como é que eles realizam sua tarefa? Não certamente dizendo que os outros são contrassensos - pois, neste caso, o "contrassenso transicional" não seria contrassenso. Tampouco mostrando que os outros são contrassensos - pois a distinção entre o que pode ser dito e o que não pode ser dito mas apenas mostrado é, segundo Diamond, contrassenso puro e simples. (HACKER, 2000, p. 361) [...] dificilmente poderíamos dizer que uma "escada" constituída por um mero amontoado de palavras sem sentido pode nos levar aonde quer que seja. (HACKER, 2001, p. 15-16)

$\mathrm{Na}$ verdade, ou bem tudo aquilo que está no interior da moldura é contrassenso, e neste caso é difícil entender como é que poderíamos ultrapassá-lo, ou então não é; mas neste caso toda a leitura que fizemos corre o risco de entrar em colapso, já que, como ficou dito nas citações que acabamos de fazer, essa leitura depende essencialmente de assumirmos a existência de um único tipo de contrassenso. Reintroduzir outra categoria pela porta dos fundos talvez não seja "fugir da raia", mas se parece bastante com roubar no jogo. 
A dificuldade é posta em evidência pelo fato de algumas sentenças no interior da moldura não serem tratadas como "contrassensos genuínos" pelos leitores "resolutos". ${ }^{26}$ Embora se tenha respondido a este ponto por meio de um apelo estropiado para a "ironia"27 (o que significa apenas dar um nome à dificuldade, mais ou menos como os políticos formam comitês sempre que desejam enterrar um problema), Diamond propôs a seguinte solução:

Você deve entender não as proposições, mas o autor. Siga, como leitor, esta orientação. Siga-a até 6.53 , onde se faz referência ao método do Tractatus. Você deve ler os contrassensos do livro e tentar entender, não os contrassensos, mas quem os escreveu. É exatamente assim que o autor do livro se propõe a responder os contrassensos ditos pelos filósofos compreendendo, não suas proposições, mas os próprios filósofos. (DIAMOND, 2000, p. 155-156)

Meu ponto, portanto, é que o Tractatus [...] pressupõe uma espécie de atividade da imaginação, um exercício da capacidade de encarar o contrassenso como se ele fosse um discurso significativo, de compartilhar imaginariamente a inclinação para se pensar que se está pensando em alguma coisa. Se eu não pudesse, por assim dizer, enxergar seu contrassenso como um sentido, e abandonar-me imaginariamente aos seus encantos, eu não poderia entendê-lo. E temos aqui um uso muito peculiar da imaginação. (DIAMOND, 2000, p. 157-158)

É fascinante perceber que aquilo que parece ser aqui o cume da sofisticação filosófica, enquanto oposta à Spitzfindigkeit, resume-se à redescoberta de uma noção hermenêutica tão tosca quanto a de Einfühlung, que na filosofia de língua alemã foi descartada há cem anos pelos críticos de Wilhelm Dilthey e Theodor Lipps. O absurdo desta última manobra ficará patente, caso nós a levemos a sério por um momento. Neste caso, Wittgenstein deve ser visto como duas personae: o autor do

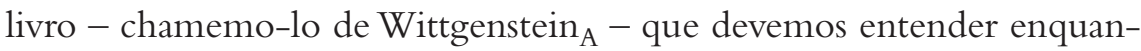
to pessoa, mas cujas únicas afirmações são aquilo que forma a moldura desse livro; e outro Wittgenstein - chamemo-lo de Wittgenstein CS $_{\text {- que }}$ é, na verdade, o incauto filósofo atraído por todo aquele amontoado de palavras sem nenhum sentido ditas por Frege, Russell \& Cia. Ao ler o 
livro, deveríamos entrar na pele deste último para, conforme se espera,

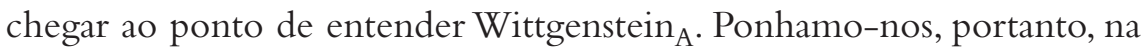
pele de Wittgenstein ${ }_{\mathrm{CS}}$, e esbocemos as opiniões sem sentido supostamente expressas pelas sequências de caracteres desprovidas de qualquer sentido nas quais percebemos a ocorrência de palavras como "matemática" e "número", isto é, 6.02-6.031 e 6.2-6.241.28 No que vem a seguir, eu de fato farei um esboço - um esboço superficial, passando por cima de numerosos problemas de interpretação que não são essenciais para a minha linha argumentativa, e permitindo-me algumas liberdades notacionais. Meu objetivo será extrair dali alguns elementos, se não de um "cálculo equacional" pleno, pelo menos de uma visão da matemática que poderia legitimar a construção de um cálculo desse tipo. Minha tese é que Goodstein fez exatamente isso.

Existem traços de um cálculo equacional no Tractatus? Há evidência textual29 de que existe uma "teoria" implícita das "operações" subjacente à abordagem da lógica e da aritmética ${ }^{30}$ do Tractatus. Em poucas palavras, Wittgenstein $_{\mathrm{CS}}$ define Formenreihe, ou "série de formas" como uma série ordenada por "relações internas" (4.1252), definindo uma relação interna como "equivalente à operação pela qual um termo surge a partir de outro" (5.232). Ainda segundo Wittgenstein ${ }_{\mathrm{CS}}$, somente por meio de uma operação, que pode tomar seu próprio resultado como base, é possível "o progresso de termo para termo numa série de formas" (5.252). Como exemplo, pode-se tomar a operação simbolizada por $\Omega$ 'x. O símbolo $\Omega$ é usado como uma variável para operações. Juntamente com o apóstrofo, ela representa o resultado da aplicação da operação, enquanto o símbolo $\mathrm{x}$ é uma variável para qualquer passo da Formenreihe. Se tomarmos a como nossa base, isto é, como não tendo resultado de nenhuma aplicação prévia da operação $\Omega$, a expressão $\Omega$ 'a representará o resultado da primeira aplicação da operação. A operação poderá, então, ser aplicada a este resultado $\Omega$ 'a, e esta nova aplicação poderá ser representada pela expressão $\Omega, \Omega$ 'a, e assim por diante. ${ }^{31}$ Deste modo, geraremos a Formenreihe a, $\Omega,{ }_{a}, \Omega, \Omega,{ }_{a}, \Omega, \Omega, \Omega,{ }_{a}, \Omega, \Omega, \Omega, \Omega ; a, \ldots$

Wittgenstein $_{\mathrm{CS}}$ propõe então em 5.2522 a introdução da seguinte "variável" para séries deste tipo (com ligeiras modificações):

$$
[a, x, \Omega, x]
$$


Em 6.02, Wittgenstein ${ }_{\mathrm{CS}}$ define (lembrem-se, no entanto, de que ainda estamos mergulhados num oceano de meros contrassensos) os números como "expoentes", isto é, como índices para aplicações reiteradas de uma operação:

$$
\begin{aligned}
& a=\Omega^{0} a \\
& \Omega^{\prime} a=\Omega^{1} a
\end{aligned}
$$

$\Omega, \Omega{ }^{\prime} a=\Omega^{2} a$

e assim por diante...

De tal modo que, após substituir apóstrofos por parênteses para modernizar um pouco a notação ${ }^{32}$, e usando a letra $\mathrm{S}$ para indicar o sucessor numa Formenreihe, obteremos a seguinte definição indutiva:

$$
\begin{aligned}
& \boldsymbol{\Omega}^{0} a={ }_{D e f} a \\
& \boldsymbol{\Omega}^{S_{n} a}={ }_{D e f} \boldsymbol{\Omega}\left(\boldsymbol{\Omega}^{n} a\right)
\end{aligned}
$$

Wittgenstein pode então sugerir em 6.03 que se introduza uma "variável" para a série dos números naturais nos moldes daquela introduzida em 5.2522:

$$
[0, \xi, \xi+1]
$$

A curiosa prova de 2 × $2=4$ em 6.241 nos ajuda a reconstruir as definições para adição e multiplicação que são necessárias em qualquer modelo para a aritmética ${ }^{33}$ :

$$
\begin{aligned}
& \boldsymbol{\Omega}^{m+n} a={ }_{D e f} \boldsymbol{\Omega}^{m}\left(\boldsymbol{\Omega}^{n} a\right) \\
& \boldsymbol{\Omega}^{n \times n} a={ }_{D e f}\left(\boldsymbol{\Omega}^{n}\right)^{m} a
\end{aligned}
$$

Dado tudo isto, a idéia é que, para quaisquer $m$ e $n$ que sejam termos numéricos, a equação

$$
m=n
$$

vale se e somente se $e^{34}$

$$
\Omega^{m} a=\Omega^{n} a
$$

Tudo isto está em consonância com as observações feitas em 6.2341 e 6.24:

6.2341 - O essencial no método matemático é trabalhar com 


\section{8}

equações. Deste método depende o fato de que toda proposição da matemática tem que ser autoevidente.

6.24 - O método pelo qual a matemática chega às suas equações é o método da substituição.

Pois as equações expressam a substitutibilidade de duas expressões, e nós avançamos de um determinado número de equações para novas equações substituindo expressões por outras de acordo com as equações.

Lello Frascolla mostrou que podemos capturar deste modo o fragmento equacional da aritmética de Peano (FRASCOLLA, 1997). Assim, correspondendo a "7 $+5=12$ ", temos “ $\Omega^{7+5} a=\Omega^{12} a$ ”, e teríamos que provar esta última equação por uma série de substituições, que no final das contas mostrariam que um lado pode ser transformado no outro, fato que registramos de maneira abreviada por meio da equação " $7+5=12$ ”. A prova completa 35 envolveria expandir o lado esquerdo, e então reescrevêlo passo a passo no lado direito a algo equivalente a

$(\Omega(\Omega(\Omega(\Omega(\Omega(\Omega(\Omega(\Omega(\Omega(\Omega(\Omega(\Omega a)))))))))))$

que, pela definição indutiva dada mais acima e pela definição de 12 , é $\Omega^{12}$ a. Que a distinção entre mostrar e dizer (4.12-4.125) está envolvida neste ponto fica claro a partir do que vem dito em 6.23:

6.23 - Se duas expressões estão conectadas pelo sinal de igualdade, isto significa que elas podem ser substituídas uma pela outra. Se isto é o caso, porém, isso deve mostrar-se nas duas expressões elas mesmas (muss sich an den beiden Ausdrücken selbst zeigen)

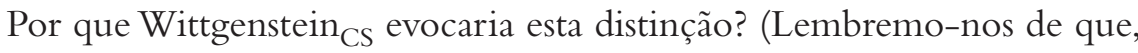
para o "Novo Wittgenstein”, a própria distinção é um contrassenso.) Porque ele queria livrar-se do apelo que Frege fazia à distinção entre sentido e referência. Esta é, pelo menos, uma das chaves para Wittgenstein $_{\mathrm{CS}}$. Com efeito, a respeito dos lados esquerdo e direito de uma equação, Wittgenstein ${ }_{\mathrm{CS}}$ afirma o seguinte:

6.232 - Frege diz que estas expressões têm a mesma referência, mas sentidos diferentes.

Mas o que é essencial a respeito de uma equação é que ela não é necessária para mostrar que as duas expressões conectadas pelo sinal de 
igualdade têm o mesmo significado: pois isto pode ser percebido (ersehen) a partir das duas expressões elas mesmas.

6.2321 - E que as proposições da matemática possam ser provadas não significa nada senão que a sua correção pode ser vista (einzusehen) sem que tenhamos que comparar aquilo que ela expressa com os fatos, no que diz respeito à correção.

6.2322 - A igualdade de significado das duas expressões não pode ser asserida. Pois, para ser capaz de asserir algo a respeito significado delas, eu tenho de conhecer o seu significado e, se conheço o seu significado, eu sei se elas significam a mesma coisa, ou a algo diferente.

6.2323 - A equação caracteriza apenas o ponto de vista a partir do qual eu considero as duas expressões, isto é, o ponto de vista da igualdade de significado (Bedeutungsgleichheit).

(grifos meus)

Ainda nos pondo na pele de Wittgenstein ${ }_{\mathrm{CS}}$, concebemos "imaginativamente" que, ao falar da Bedeutungsgleichheit de $\Omega^{m} a=\Omega^{n}$ a ele queria dizer que é possível ver que o lado esquerdo é transformado no lado direito. Isto pode ser visto porque é algo que se mostra. Antes de prosseguir, gostaria de enfatizar a importância da distinção entre mostrar e dizer para Wittgenstein $_{\mathrm{CS}}$, importância esta que é patenteada pelo uso repetido, não apenas de zeigen, como também de palavras como ersehen ou erkennen. Ocorrências similares podem ser encontradas em observações referentes à lógica (novamente, os grifos são meus):

6.113 - É marca característica das proposições lógicas que podemos perceber (erkennen) apenas a partir do símbolo se elas são verdadeiras, e este fato contém em si toda a filosofia da lógica.

$[\ldots]$

6.126 - Que uma proposição pertença à lógica é algo que pode ser calculado calculando-se as propriedades lógicas do símbolo. E nós fazemos isso quando provamos uma proposição lógica. Pois, sem nos preocuparmos a respeito de sentido e significado, formamos a proposição lógica a partir de outras apenas através de regras simbólicas. Provamos uma proposição lógica criando-a a partir de outras proposições lógicas mediante aplicações sucessivas de certas operações que novamente geram tautologias a partir das primeiras. [...] 
Naturalmente, este modo de mostrar (zeigen) que suas proposições são tautologias é completamente inessencial para a lógica. Pois as proposições de que a prova partiu devem mostrar (zeigen müssen) sem nenhuma prova que elas são tautologias.

6.1262 - Na lógica, a prova é apenas um expediente mecânico para facilitar o reconhecimento (Erkennen) de uma tautologia, quando esta é complicada [grifos meus].

Tentarei mostrar que este uso da distinção entre mostrar e dizer enquanto um dos tijolos, digamos assim, de seu cálculo equacional, é absolutamente central para a abordagem da aritmética feita por Wittgenstein ${ }_{\mathrm{CS}}$, já que diversas alegações suas só podem ser "entendidas" (lembremo-nos de que falamos aqui sobre Wittgenstein ${ }_{\mathrm{CS}}$ ) com base nessa distinção.

$\mathrm{Na}$ proposição 6.2, Wittgenstein ${ }_{\mathrm{CS}}$ alega que na aritmética há equações, e que estas são Scheinsätze. Por que estas equações devem apenas ter a aparência de "proposições"? Presumivelmente porque poderíamos ler"7 $+5=12$ " como "Sete mais cinco são doze". Veremos que esta é uma distinção muito importante, mas por que Wittgenstein ${ }_{C S}$ deveria se importar com o fato de haver uma diferença entre a equação e seu correspondente no português? Obviamente, como o cálculo lógico aplica-se a "proposições", o efeito direto da dissociação entre essas duas coisas é fazer com que o cálculo lógico não se aplique a equações. Noutras palavras, Wittgenstein ${ }_{C S}$ deseja enfatizar as diferenças entre a equação aritmética " $7+5=12$ " e o seguinte, escrito na linguagem dos Principia Mathematica (note a presença dos quantificadores) ${ }^{36}$ :

$$
\exists !{ }_{7} x F(x) \wedge \exists !{ }_{5} x G(x) \wedge(\forall x \neg(F(x) \wedge G(x))) \equiv \exists !{ }_{12} x F(x) \vee G(x)
$$

Eis aqui, agora, a idéia chave: esta sentença russelliana diz aquilo que a prova de "7 $7=12$ " mostra. É importante também entender que a linguagem na qual escrevemos a equação " $7+5=12$ ” e na qual a provamos não é idêntica à linguagem lógica dos Principia Mathematica, na qual essa equivalência é provada como algo que lhe corresponde. Como Wittgenstein dirá mais tarde, elas não têm a mesma "gramática”. E, claramente, Wittgenstein ${ }_{\mathrm{CS}}$ está querendo sustentar que a prova de " $7+5=$ 12 " numa linguagem não equivale a uma prova daquilo que lhe corresponde numa outra linguagem (lógica). (Há muitas coisas na filosofia da 
matemática madura de Wittgenstein a respeito da alegação de que estas duas linguagens, no final das contas, não estão relacionadas, e que uma não é o fundamento da outra.) Talvez valha a pena citar as Observações Filosóficas para mostrar que Wittgenstein tinha de fato algo deste tipo em mente durante todo esse tempo:

O importante é que, mesmo que $3^{2}+4^{2}=5^{2}$ me seja dado, eu não posso dizer " $(\exists x, y, z, n) \cdot x^{\mathrm{n}}+y^{\mathrm{n}}=z^{\mathrm{n}}$ ”, pois tomado extensionalmente isso não faz sentido, e tomado intensionalmente isso não me dá uma prova. Não, nesse caso devo expressar apenas a primeira equação. (WITTGENSTEIN, 1975, \$150; daqui em diante, PR)

Wittgenstein está empregando aqui a distinção entre intensional e extensional, mas não é ela que tem importância para nós. Devemos, ao invés disso, prestar atenção quando ele afirma que a equação aritmética não fornece uma prova de seu correspondente na lógica. Onde encontrar um argumento em favor disto? Voltarei a este ponto quando estivermos discutindo a substituição da indução pela unicidade.

Por ora, quero apenas ressaltar que o argumento poderia, em consonância com outras opiniões expressas por Wittgenstein CS $_{\text {, girar em }}$ torno da idéia de que a prova aritmética mostra algo, e que seu correspondente lógico diz isso. E, talvez, esta tentativa de dizer na linguagem dos Principia Mathematica aquilo que se mostra na linguagem da teoria das operações (ou, mais tarde, na aritmética recursiva primitiva) é precisamente aquilo que acaba levando ao contrassenso. E trata-se de um contrassenso porque, no interior da linguagem da teoria das operações, não atribuímos nenhuma Bedeutung ao vocabulário dos Principia Mathematica (seguindo, aqui, o que vem dito em 5.4733 e 6.53). Parece-me que isto nos dá uma das chaves para a compreensão do Tractatus.

\section{De Wittgenstein a Goodstein}

Isto nos dá um primeiro ponto de contato com o cálculo equacional de Goodstein. Na verdade, aquilo de que Wittgenstein ${ }_{C s}$ precisa para que seu argumento tenha algum impacto, mas que ele não nos fornece, é uma abordagem da aritmética que esteja "livre da lógica". O cálculo equa- 


\section{2}

cional de Goodstein consiste naquilo que é conhecido como um cálculo de "variáveis livres", e está efetivamente "livre da lógica". No cálculo equacional, todas as proposições são equações da forma

$$
A=B
$$

onde A e B são funções primitivas recursivas, ou termos. As regras de substituição são as seguintes:

$$
\frac{F(x)=G(x)}{F(A)=G(A)} \quad \frac{A=B}{F(A)=G(B)} \quad \frac{A=B \quad A=C}{B=C}
$$

E a regra de unicidade é semelhante à que demos mais acima. Uma prova é uma tabela de equações, cada uma das quais é a definição de uma função, uma equação da forma $A=A$, ou uma equação já "demonstrada” (GOODSTEIN, 1957a, p. 27), não sendo necessário incluir qualquer referência a conectivos ou regras proposicionais na formalização. ${ }^{37}$ Ele não precisa, portanto, incluir referências a tais coisas em seu sistema de aritmética recursiva primitiva, no qual as funções aritméticas são introduzidas por meio de definições recursivas, evitando-se assim todo o aparato da teoria da quantificação. Esta é uma característica importante: a universalidade vem expressa por variáveis livres, ao passo que a existência é expressa por uma função recursiva. Isto está em perfeito acordo com outra tese, referente à quantificação, obscuramente expressa por Wittgenstein $_{\mathrm{CS}}$ em 5.521, onde ele fala a respeito de separar o "todo" das funções de verdade, ou em 5.523, onde ele associa a generalidade ao " $x$ " de " $F(x)$ ". Podemos presumir que ele queira dizer que a generalidade é expressa pelo uso de uma variável, que determina uma classe de proposições (havendo, segundo 5.501, três modos de se fazer isso), enquanto um operador tem que ser aplicado a esta classe para expressar o fato de que todas ou algumas de suas proposições são verdadeiras.

Voltando ao Wittgenstein ${ }_{\mathrm{CS}}$, não fiquemos parados nas razões que ele poderia ter para negar o estatuto de "proposição" às equações aritméticas. ${ }^{38}$ Ao invés disso, devemos perguntar: Ele possui um argumento? Em 6.21, ele nos diz (mas lembre-se - isto tudo não passa de um amontoado de palavras sem sentido ditas por Wittgenstein ${ }_{\mathrm{CS}}$ ) que as equações aritméticas "não expressam pensamentos". Seus critérios para decidir se algo é uma proposição não são meramente gramaticais, já que proposições são 
feitas para figurar fatos, o que é idêntico a expressar pensamentos.Vamos, portanto, inferir "imaginativamente" que isto significa que não há "fatos" que as equações possam figurar. Filósofos iludidos infeririam neste ponto

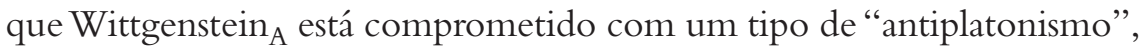
ou de "antirrealismo" segundo o qual não existem "objetos" dos quais os termos aritméticos seriam os representantes, nem a fortiori conexões entre tais "objetos" em "fatos" que seriam afigurados pelas "proposições" aritméticas. Isto faria algum sentido, já que é coerente com a definição dos números enquanto índices de aplicações reiteradas de uma operação. Mas, na verdade, nós só estamos falando aqui a respeito de Wittgenstein $_{\mathrm{CS}}$, não é mesmo?

Seja como for, em 6.211, Wittgenstein ${ }_{\mathrm{CS}}$ escreveu:

$\mathrm{Na}$ vida, nunca é da proposição matemática que necessitamos, mas usamos a proposição matemática apenas para inferir proposições que não pertencem à matemática a partir de outras que também não pertencem à matemática.

Este ponto de vista implica que não existem “objetos” na aritmética, já que esta é formada apenas por cálculos que nos levam de uma "proposição" genuína, não aritmética, a outra "proposição" genuína e não aritmética. Da mesma forma, ele nos ensina por que não deveríamos ver uma equação aritmética como uma asserção a respeito da identidade de seus termos, pois isto seria, como Michael Kremer percebeu corretamente, tomá-la como premissa numa inferência de "proposição" a "proposição", quando ela é apenas o cálculo envolvido na execução da inferência - é parte da inferência (KREMER, 2002, p. 293). Kremer tentou mostrar, além disso, que as equações aritméticas deveriam ser, por isso, interpretadas como "registros" dos cálculos que nos levam de uma "proposição” genuína até outra (KREMER, 2002, p. 294). A meu ver, isto está correto, mas tem de ser qualificado: é a equação "7 $+5=12$ ", ou ainda o conjunto de equações da teoria das operações com as quais nós a provamos, que é o próprio "registro", mas é preciso não confundila com a versão que encontramos na linguagem ordinária, isto é, "sete mais cinco é igual a doze", ou então o correspondente lógico que vimos mais acima, no estilo dos Principia Mathematica. Estas últimas afirmam aquilo que as equações, enquanto "registro", mostram. Se confundirmos estas 


\section{4}

duas coisas, teremos a tendência a pensar em " $7+5=12$ " como uma asserção de identidade, e aumentar ainda mais a confusão, pensando que esta asserção é a premissa de uma inferência.

Outro critério para ser uma "proposição" bona fide, segundo Wittgenstein $_{\mathrm{CS}}$, é possuir "bipolaridade", isto é, a capacidade de ser verdadeira $e$ também de ser falsa. Em outras palavras, é essencial para uma proposição que ela deva ser capaz de ser negada. No entanto, tendo entrado imaginativamente na cabeça de Wittgenstein ${ }_{\mathrm{CS}}$, acreditamos também que isto não acontece com as equações, pois não podemos imaginar sob quais circunstâncias estaríamos preparados para asserir suas negações, por exemplo,

Se digo que 7 não é divisível por 3, eu não consigo nem mesmo fazer uma figuração disto, eu não posso imaginar o que aconteceria se 7 fosse divisível por 3. (PR, $\$ 200)^{39}$

Que isto seja uma consequência das opiniões sustentadas por Wittgenstein $_{\mathrm{CS}}$ é algo que foi indicado pela primeira vez en passant por Ramsey (RAMSEY, 1923, p. 476). ${ }^{40}$

Estas duas razões para negar status "proposicional" às equações aritméticas estão em perfeita sintonia com o cálculo equacional de Goodstein. $\mathrm{Na}$ verdade, correspondem muito claramente à visão algorítmica corporificada em 6.211, pois (conforme já foi dito) a existência é expressa por uma função recursiva, etc.Veremos que a importância da substituição da indução pela unicidade torna-se significativa nesse contexto. A ausência de bipolaridade é mais um ponto de contato com o cálculo equacional de Goodstein, algo que é mais dificil de ver e, em função disso, permaneceu despercebido. ${ }^{41}$ Para perceber isto, no entanto, é preciso passar por alguns desenvolvimentos, que vêm a seguir.

Até aqui, eu deliberadamente passei por alto inúmeras dificuldades associadas ao meu entendimento "imaginativo" de Wittgenstein ${ }_{\mathrm{CS}}$. É fácil perceber que uma dificuldade central é o fato de Wittgenstein ${ }_{\mathrm{CS}}$ precisar de uma abordagem da indução matemática ou recursão que ele não fornece.Vem daí a reclamação de que sua abordagem não passa de uma miscelânea de alegações e fórmulas estranhas (MAYBERRY, 2000, p. 271 n.7). A noção de recursão primitiva foi introduzida, juntamente com a aritmética recursiva, por Thoralf Skolem em 1923 - dois anos após a publicação do Tractatus, portanto (SKOLEM, 1967) - e a arit- 
mética recursiva primitiva foi depois desenvolvida por Hilbert \& Bernays, naquilo que é hoje o locus classicus para esse tema - o primeiro volume das monumentais Grundlagen der Mathematik (HILBERT \& BERNAYS, 1934, p. 286-346). Wittgenstein, portanto, não poderia se valer da noção, e só poderia ser censurado por não tê-la inventado. Mesmo assim, a falta de qualquer tratamento da indução ou da recursão é realmente um defeito. Os manuscritos do "período intermediário" mostram que Wittgenstein tinha consciência disso, pois prestou a máxima atenção ao artigo de Skolem (do qual se sabe que ele tinha uma cópia), por exemplo, no capítulo XIV das Observações Filosóficas. Na sequência, porei o foco sobre as seções relevantes do Big Typescript, a saber, aquelas que constituem seu décimo oitavo capítulo, intitulado "Provas indutivas, periodicidade" (BT, \$\$126-135), que já citei anteriormente. ${ }^{42}$ Como era de esperar, Wittgenstein compacta inúmeras linhas argumentativas nestas seções, e os parágrafos a seguir não têm de maneira alguma a pretensão de exaurir o seu conteúdo. São, antes, uma primeira incursão no tema.

Podemos começar recordando como é feita a demonstração de Skolem. Dada a seguinte definição recursiva da adição:

$$
\begin{aligned}
& a+0=a \\
& a+(b+1)=(a+b)+1
\end{aligned}
$$

a prova apresentada por Skolem para a lei associativa

$$
\text { (A) } a+(b+c)=(a+b)+c
$$

é feita do seguinte modo. ${ }^{43}$ Para o caso base:

Se $c=0$, então $(a+b)=(b+a)$, já que $a+0=a$.

Para o passo indutivo, supomos que a lei associativa vale para um certo valor $\mathrm{C}$ de $\mathrm{c}$, de modo que temos:

(i) $a+(b+(C+1))=a+((b+C)+1)$ (por definição)

(ii) $\mathrm{a}+((\mathrm{b}+\mathrm{C})+1)=(\mathrm{a}+(\mathrm{b}+\mathrm{C}))+1$ (por definição)

(iii) $(\mathrm{a}+(\mathrm{b}+\mathrm{C}))+1=((\mathrm{a}+\mathrm{b})+\mathrm{C})+1$ (por hipótese de indução)

(iv) $((\mathrm{a}+\mathrm{b})+\mathrm{C})+1=(\mathrm{a}+\mathrm{b})+(\mathrm{C}+1)$ (por definição)

$$
\mathrm{a}+(\mathrm{b}+(\mathrm{C}+1))=(\mathrm{a}+\mathrm{b})+(\mathrm{C}+1) \quad(\text { por }(\mathrm{i}),(\mathrm{ii}),(\mathrm{iii}),(\mathrm{iv}))
$$




\section{6}

Em conformidade com (BT, p. 445), chamemos de (B) esta estrutura formada pelo caso base e pelo passo indutivo. Isto facilitará a discussão que vem a seguir. Segundo Skolem, o passo indutivo mostra que, se a lei associativa vale para um valor $\mathrm{C}$ de $\mathrm{c}$, então ela também vale para o valor $\mathrm{C}+1$ de c. Deve-se notar a escolha vocabular cuidadosa feita por Skolem ao fazer seus comentários. Segundo ele, isto

$[\ldots]$ prova a proposição $c+1$ para $a$ e $b$ não especificados. A

proposição, portanto, vale de modo geral. Este é um exemplo típico de prova recursiva (prova por indução matemática). (SKOLEM, 1967, p. 603)

Não há quantificadores envolvidos, nem alegações de se ter provado (A) "para todos" os valores numéricos de $a, b$ e $c$, em proposições do tipo:

(C) $\forall \mathrm{x} \forall \mathrm{y} \forall \mathrm{z} x+(\mathrm{y}+\mathrm{z})=(\mathrm{x}+\mathrm{y})+\mathrm{z}$

Antes de discutirmos os comentários que Wittgenstein faz a esta prova, vejamos como ele introduz a "unicidade". ${ }^{44}$ Wittgenstein não reclama de que Skolem teria acreditado ter provado $(\mathrm{C})$ - ele obviamente não acreditava nisso. Como diz Wittgenstein,

Eu descubro que em nenhum lugar de meu cômputo eu uso a

proposição a respeito de "todos os números cardinais". (BT, p. 455)

(PG, p. 410)

Wittgenstein tinha inúmeras coisas a dizer a respeito da relação que a estrutura (B) e a estrutura $\Delta$ abaixo tinham com a estrutura (C). Por exemplo, ele reclama:

O que você chama de uma prova de que um teorema vale para todos os números cardinais? Como você sabe se um teorema é (realmente) válido para todos os números cardinais, dado que você não pode testálo? Afinal de contas, seu único critério é a própria prova. Assim, com toda a probabilidade você estipula uma forma e a chama de forma da prova de que uma proposição vale para todos os números cardinais. Nesse caso, nós realmente não ganhamos nada por nos mostrarem primeiro a forma geral destas provas, porque isso não mostra que a prova individual realmente efetua aquilo que demandamos dela. Quero dizer que essa forma não justifica, não mostra que a prova individual é 
uma prova de um teorema para todos os números cardinais. Pelo contrário, a prova recursiva tem de ser sua própria justificativa. (BT, p. 462) (PG, p. 422)

Mas ele também tinha restrições quanto a

(A) segue-se de (B)

pois (A) não ocorre em (B), e é difícil ver como aquela única "proposição" (A) se seguiria do conjunto de equações constitutivas de (B), mesmo se formássemos uma corrente com elas, unindo-as com " $\&$ ". As piores dificuldades, porém, surgem aqui no uso da Wortsprache, ou seja, com expressões correspondentes na linguagem verbal, tais como "Sete mais cinco são doze":

Mas, não posso dizer que, se provei isto sobre $\mathrm{A}$, eu por isso mesmo provei A? Se não posso, de onde vem a ilusão de que provei? Pois certamente deve existir alguma razão profunda para essa ilusão. Bem, se é uma ilusão, ela em todo caso surgiu de nosso modo de expressão na linguagem verbal, "Esta proposição vale para todos os números". Pois, de acordo com este ponto de vista, a proposição algébrica seria apenas outro modo de escrever a proposição (da linguagem verbal). E esta forma de expressão permitiu que o caso de todos os números fosse confundido com o caso de "todas as pessoas nesta sala". (Ao passo que, para distinguir os casos, nós perguntamos: como verificamos a primeira, e como verificamos a outra?) (BT, p. 457) (PG, p. 413)

E, dado que a linguagem verbal, ao explicar a prova (isto é, aquilo que a prova está provando), apenas a traduz numa outra forma de expressão, podemos simplesmente excluir esta explicação de uma vez. E, se fizermos isso, as relações matemáticas tornam-se muito mais claras, pois não ficam mais turvadas por expressões da linguagem verbal com sentidos [ambíguos]. Por exemplo, se puser B simplesmente ao lado de A, sem usar a expressão da linguagem verbal "para todos os números cardinais, etc.", não surgirá nenhuma falsa aparência de uma prova de A por meio de B.Vemos [sehen], então, as relações austeras (simples) entre $\mathrm{A}$ e B, e até que ponto elas se estendem. Apenas deste modo, livres da confusão causada pela forma da linguagem verbal, que tudo nivela, é 


\section{8}

que chegamos a conhecer a real estrutura daquela relação, e de que ela trata. (BT, p. 462) (PG, p. 422)

A distinção entre mostrar e dizer está envolvida neste ponto:

"Esta proposição está provada para todos os números pelo

procedimento recursivo." Esta é a expressão que nos desencaminha

tanto. Tudo se passa, aqui, como se tivéssemos mostrado, por um

determinado caminho, a verdade de uma proposição afirmando que tal

e tal coisa vale para todos os números cardinais, e como se este

caminho fosse um caminho no interior de um espaço de caminho concebível.

Ao passo que, na realidade, a recursão não mostra [zeigt] nada além de si mesma [...] (BT, p. 453) (PG, p. 406) 45

Noutras palavras, a prova recursiva pode, no máximo, mostrar a generalidade, mas, embora possamos afirmar essa generalidade usando um enunciado aritmético universalmente quantificado, este enunciado estaria indo além daquilo que a prova mostra, não respeitando assim a gramática específica da linguagem algébrica da prova.

Como ressaltou Mitsu Okada (OKADA, 2007, p. 124-128), em "(A) segue-se de (B)", Wittgenstein pôs o foco sobre a noção de "segue-se de". Em sua forma usual (I), a indução matemática usa, não apenas o quantificador universal, mas também - duas vezes - a implicação " $\rightarrow$ ”: uma vez no passo de indução, e outra vez na passagem do caso de base e do passo de indução para o enunciado universalmente quantificado. $\mathrm{O}$ incômodo de Wittgenstein incide sobre o "segue-se de" envolvido na segunda implicação. Pode-se, é claro, fornecer uma versão da indução que evita todas estas preocupações. Basta evitar o uso de " $\forall$ " ou de " $\rightarrow$ ", como nesta versão da indução de Skolem em dedução natural:46

$$
\begin{gathered}
\varphi(c)=\psi(c) \\
\cdot \\
\cdot \\
\frac{\varphi(0)=\psi(0) \quad \varphi(c+1)=\psi(c+1)}{\varphi(c)=\psi(c)}
\end{gathered}
$$


Acabamos de ver que ele não poderia aceitar que aquilo que a recursão mostra possa ser capturado por um enunciado aritmético universalmente quantificado que seria simplesmente adicionado como um último passo da prova. Isto porque, como mostrou Okada, Wittgenstein achava que equações algébricas e enunciados universalmente quantificados possuem diferentes "gramáticas", e este último passo não estaria respeitando a gramática das equações algébricas (OKADA, 2007, p. 124-125). Preste-se atenção à referência feita ao "contra-senso":

Assim, a proposição que afirma a generalização é excluída; "nada é provado", "nada se segue".

"Certo, mas a equação A se segue, sim; ela agora toma o lugar da proposição geral.” - Bem, segue-se em que medida? Obviamente, estou usando "seguir-se", aqui, num sentido completamente diferente do usual, pois aquilo de que A se segue não é uma proposição. E é por isso que nós sentimos que a palavra "seguir" não foi aplicada corretamente. Quando dizemos "Do complexo B, segue-se que $a+(b+c)=(a+b)$ $+c$ ", temos uma vertigem. Sentimos que, de algum modo, dissemos um contrassenso (Unsinn), muito embora externamente isso soe como algo correto.

Que uma equação se segue é algo que já tem um sentido (tem uma gramática própria, particular).

No entanto, quando ouço "A segue-se de B", tenho vontade de perguntar: "O que se segue?" Caso não se siga de uma equação do modo usual, que $a+(b+c)$ seja igual a $(a+b)+c$ não passa de uma estipulação.

Não podemos impor nosso conceito de "seguir-se" a A e B; ele não se ajusta ali. (BT, p. 455) (PG, p. 410-411)

Se não é o caso que “(A) segue-se de (B)”, e se deve ser ponto pacífico que (B) não prova algo como (C), então Wittgenstein está obrigado a reformular o esquema de indução. Como nos explica Goodstein, o argumento é o seguinte. ${ }^{47}$ Wittgenstein começa se perguntando por que alguém suporia que a lei associativa se aplica a um valor de $c$. Por que não supor simplesmente que ela valha para qualquer $c$ ? Ele então reescreve a prova do seguinte modo, usando $\mathrm{S}$ para representar a função sucessor: 


$$
\begin{aligned}
& (\mathrm{a}+\mathrm{b})+(\mathrm{c}+1)=\mathrm{S}((\mathrm{a}+\mathrm{b})+\mathrm{c}) \\
& \mathrm{a}+(\mathrm{b}+(\mathrm{c}+1))=\mathrm{a}+((\mathrm{b}+\mathrm{c})+1)=\mathrm{S}(\mathrm{a}+(\mathrm{b}+\mathrm{c}))
\end{aligned}
$$

Ele então nos faz notar que

$$
(a+b)+(c+1)
$$

é a mesma função $S$ de

$$
(a+b)+c
$$

que

$$
a+(b+(c+1))
$$

é de

$$
a+(b+c)
$$

Como

$$
(a+b)+0=a+(b+0),
$$

segue-se que poderíamos obter

$$
(\mathrm{a}+\mathrm{b})+\mathrm{c} \text {, e também } \mathrm{a}+(\mathrm{b}+\mathrm{c})
$$

aplicando a função $\mathrm{S}$ a a $+\mathrm{b}$ o mesmo número de vezes, de tal modo que

$$
(a+b)+c=a+(b+c)
$$

$\mathrm{Na}$ verdade, o que Wittgenstein fez aqui foi substituir a indução pela unicidade. Em (BT, p. 445) (PG, p. 397), ${ }^{48}$ ela é apresentada do seguinte modo, como um correspondente exato do esquema $(U)$ dado mais acima:

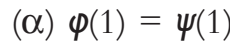

(ß) $\varphi(c+1)=F(\varphi(c)) \quad\} \quad \varphi(c)=\psi(c) \ldots \Delta$

$(\gamma) \psi(c+1)=F(\psi(c))$

Com o seguinte comentário:

[...] a questão de saber se $\mathrm{A}$ é válido para todos os números cardinais deve significar: "As equações $\alpha, \beta$ e $\gamma$ são válidas para as funções $\varphi(\xi)=$ $\mathrm{a}+(\mathrm{b}+\xi)$ e $\psi(\xi)=(\mathrm{a}+\mathrm{b})+\xi$ ? E, então, essa questão terá sido 
respondida pela prova recursiva de $\mathrm{A}$, se por isto entendemos as provas de $\alpha, \beta$ e $\gamma$. (BT, p. 445-446) (PG, p. 398)

De passagem, pode-se notar a variante notacional do próprio Wittgenstein, que é derivada do Tractatus, onde a "forma geral do número cardinal" é apresentada em 6.03 da seguinte forma:

$[0, \xi, \xi+1]$

A forma correspondente no Big Typescript (BT, p. 469-470) (PG, p. 431433) torna-se:

$$
|1, \xi, \xi+1|
$$

Então, “a $+(b+1)=(a+b)+1$ " é reescrita do seguinte modo (BT, p. $461 \& 470)(\mathrm{PG}$, p. 420 \& 433):

$$
\left[\begin{array}{cc}
a+(1+1) & (a+1)+1 \\
\quad \downarrow & \downarrow \\
a+(\xi+1) & =(a+\xi)+1 \\
a+((\xi+1)+1) & =((a+\xi)+1)+1
\end{array}\right]
$$

que deve, agora, percorrer a série $|1, \xi, \xi+1|$. No Tractatus, Wittgenstein $_{\mathrm{CS}}$ aparentemente dissociou a generalidade dada em séries como $|1, \xi, \xi+1|$ das funções de verdade, isto é, dos quantificadores. Wittgenstein volta a insistir no mesmo ponto:

Não devemos, porém, achar que este sinal devesse ser, na verdade, “( $(\xi)|1, \xi, \xi+1| "$.

O ponto de nossa apresentação consiste em que o conceito "todos os números" foi dado apenas por uma estrutura como $\mid 1, \xi$, $\xi+1 \mid$. A generalidade foi apresentada por esta estrutura no simbolismo, e não pode ser descrita por algo do tipo (x).fx. (BT, p. 469) (PG, p. 431-432)

Por que Wittgenstein teria sentido a necessidade de fazer tudo isto? Uma (suposta) vantagem é a clareza conceitual, na medida em que a "linguagem verbal" e a lógica são mantidas sob controle. Não há risco de alguém alegar que $\Delta$ é uma prova de (C). Mas isto, como vimos, já é verdade acerca da prova de Skolem. Além disso, não estamos mais próximos de uma transição para (A) quando temos $\Delta$ ao invés de (B): 
Em todo caso, é desencaminhador dizer que provamos a equação $\Delta$, ou A. Talvez seja melhor dizer que provamos sua validade geral, muito embora, de outro ponto de vista, isto também seja desencaminhador. (BT, p. 445) (PG, p. 449)

Enquanto regra para o cálculo algébrico, A não pode ser provada recursivamente. (BT, p. 481) (PG, p. 449)

Talvez os dois pontos seguintes lancem alguma luz sobre isto. Primeiramente, devemos entender que, do começo ao fim, Wittgenstein mantém a álgebra separada da teoria dos números. Elas são, para ele, cálculos diferentes: linguagens diferentes com "gramáticas" diferentes. Há um "golfo" separando-as (BT, p. 481) (PG, p. 449), de tal modo que uma prova indutiva - ou prova por unicidade - em uma não é capaz de provar uma equação aritmética universal na outra:

Uma prova por indução, se fosse uma prova, seria uma prova de generalidade, e não a prova de uma determinada propriedade de todos os números. (PR, \168)

Desse modo, achamos estranho quando nos dizem que a indução prova a proposição universal; pois temos a sensação correta de que, na linguagem da indução, não poderíamos nem mesmo ter feito a questão universal. (BT, p. 449) (PG, p. 402)

Não podemos, portanto, interpretar uma equação geométrica aberta como se ela fosse uma equação aritmética universal. ${ }^{49}$ Segundo Wittgenstein, o que ocorre é que o cálculo algébrico - a Buchstabenrechnung 50 - e o cálculo dos números cardinais entram em contato na prova recursiva:

Naturalmente, o propósito de uma "prova recursiva" é conectar o cálculo algébrico ao cálculo numérico. E a árvore das provas recursivas apenas "justifica" o cálculo algébrico se com isto queremos dizer que ela o conecta ao cálculo aritmético. (BT, p. 462) (PG, p. 423)

E é isso que a prova de Skolem nos mostra:

[...] uma conexão entre os paradigmas da álgebra e as regras do cálculo da aritmética. (BT, p. 463) (PG, p. 423)

[Isso] produz um uníssono entre o cálculo [algébrico] e o cálculo dos números cardinais. (BT, p. 481) (PG, p. 449) 
Como ressaltou Okada (OKADA, 2007, p. 127), a razão desta observação é que a conexão entre as duas gramáticas não é feita dentro de uma metalinguagem, mas, por assim dizer, diretamente. Em que consistiria, porém, tal conexão? Penso, muito simplesmente, que Wittgenstein percebeu que a prova recursiva fornece um molde para provas aritméticas particulares, nas quais as variáveis são substituídas por numerais. ${ }^{51}$ Eis aqui algumas passagens que confirmam isto:

Uma prova recursiva é apenas um guia geral para uma prova especial arbitrária. Um sinalizador indicando a cada proposição de uma forma específica um caminho específico para casa. (PR, \$164)

Sua generalidade não reside nela mesma, mas sim na possibilidade de sua correta aplicação. Para tanto, ela deve continuar recorrendo à indução. Isto é, ela não diz sua generalidade, ela não a expressa. Antes, a generalidade é mostrada na relação formal com a substituição, que se revela como elo da série indutiva. (PR, \$168)

Uma "prova recursiva" é o termo geral de uma série de provas. Ela é, portanto, uma lei para a construção de provas. Se se pergunta como esta forma geral pode fazer economia da prova de uma proposição particular, tal como $7+(8+9)=(7+8)+9$, a resposta é que ela simplesmente deixa tudo pronto para a prova desta proposição, mas não a prova (na verdade, a proposição não ocorre nela). A prova consiste, pelo contrário, na forma geral juntamente com a proposição. (BT, p. 468) (PG, p. 430)

É claro que a assim chamada "definição recursiva" não é uma definição no sentido usual da palavra, pois ela não é uma equação, já que a equação " $a+(b+1)=(a+b)+1$ " é apenas parte dela. Ela também não é um produto lógico de equações. Ela é antes uma lei para a construção de equações, da mesma forma que $|1, \xi, \xi+1|$ não é um número, mas apenas uma lei, etc. (BT, p. 469) (PG, p. 432)

Isto tudo está (em linhas gerais) de acordo com o que disseram Skolem e, mais tarde, Hilbert \& Bernays. Estes últimos viram neste ponto a chave para um argumento para estabelecer a consistência da aritmética recursiva primitiva (HILBERT \& BERNAYS, 1934, p. 298-299)52. Essas observações filosóficas não têm apenas um valor histórico, uma vez que Alan Bundy e seus colaboradores introduziram recentemente, 


\section{4}

sem qualquer conhecimento dessas observações ${ }^{53}$, uma distinção entre provas "hilbertianas" e "esquemáticas" (acerca de números naturais como tipos de dados recursivos) que é essencialmente paralela à distinção que Wittgenstein procurava traçar (BUNDY, JAMNIK \& FUGARD, 2005). Eles usam a regra $\omega$ construtiva para estabelecer programas recursivos que formalizam provas esquemáticas e até mesmo levantam a hipótese de que estas últimas podem servir de modelos cognitivos para homens, os quais obviamente não usam provas hilbertianas para determinar a verdade ou falsidade de conjeturas. O paralelo com as idéias de Wittgenstein bem merece maiores investigações, mas, pelo momento, cumpre apontar uma diferença óbvia. Bundy, Jamnik \& Fugard exigem uma etapa final de verificação por indução de que o programa constrói uma prova para cada número natural $n$, dado que, na ausência dessa etapa de verificação "será por pura sorte que uma prova esquemática venha a produzir uma prova adequada para cada exemplo" (BUNDY, JAMNIK \& FUGARD, 2005, p. 2384). É o que não parece ter ocorrido a Wittgenstein.

Neste ponto, haveria muitas outras coisas a serem ditas, mas eu me limitarei a fazer apenas alguns comentários com a finalidade de elucidar um ponto que deixei inexplicado mais acima, a saber, a possibilidade de se fazer uma conexão entre o cálculo equacional de Goodstein e a ausência de bipolaridade nas equações aritméticas do Tractatus. Antes disso, porém, gostaria de observar de passagem que tudo isso que vimos até agora não deveria ser desconsiderado simplesmente por ser parte do "período intermediário". É frequente ouvirmos que os escritos deste período são meramente transicionais, e usar observações deste tipo para canhestramente desqualificar quaisquer alegações substantivas feitas com base nestes escritos, como se, no Tractatus e, mais tarde, nas Investigações, Wittgenstein não estivesse disposto a afirmar nada disto, e tivesse apenas, de maneira equivocada e tola, sustentado estas teses por um período breve e sem importância. O fato é que não existe nos escritos da maturidade nenhum movimento indo numa direção diferente, e por isso uma atitude como essa que descrevemos só pode ter por base a ignorância, ou mesmo a arrogância. É claro que isto não pode ser demonstrado aqui, mas qualquer um que acredite em semelhantes coisas deveria ponderar em observações como estas, escritas em 1939-1940: 
Uma desvantagem psicológica das provas que constroem proposições é que elas facilmente nos fazem esquecer que o sentido do resultado não deve ser extraído dele sozinho, mas da prova. A este respeito, a intrusão do simbolismo russelliano nas provas trouxe muitos maleficios.

(WITTGENSTEIN, 1978, III, \$25; daqui em diante RFM)

É muito provável que a expressão verbal do resultado de uma prova matemática seja calculada para nos iludir com um mito. (RFM, III, \$26)

O argumento era que as equações aritméticas não são "proposições" genuínas porque lhes falta a propriedade essencial de poderem ser verdadeiras e poderem ser falsas. Acabamos de ver que Wittgenstein compreendia as provas recursivas como sendo distintas dos enunciados aritméticos universais que são normalmente considerados como aquilo que foi provado por essas provas.Vimos também que Goodstein dispensou completamente a teoria da quantificação em seu cálculo equacional, para o qual ele utilizou a reformulação proposta por Wittgenstein do esquema de indução em termos de uma regra de unicidade. Juntando estas coisas, podemos ver agora que o cálculo equacional de Goodstein se parece bastante ao Tractatus exatamente por essa razão: não existem ali fórmulas com quantificadores (sentenças) que possam ser negadas, apenas fórmulas com variáveis livres, e estas não podem ser negadas. Na verdade, a alegação de que uma lei como (A) não possui uma contraditória e não pode ser negada é repetida muitas e muitas vezes no Big Typescript, p.ex., em (BT, p. 446, 448, 449, 470) (PG, p. 399, 400, 401, 433-434).

Vale a pena observar de passagem que o que acabamos de dizer explica algumas alegações prima facie absurdas que encontramos nas Observações Filosóficas:

Se a prova de que toda equação tem uma raiz é uma prova recursiva, então isso significa que o Teorema Fundamental da Álgebra não é uma proposição matemática genuína. (PR, \$168)

Eu digo: o chamado "Último Teorema de Fermat" não é uma proposição. (Nem mesmo no sentido de uma proposição da aritmética.) Ao invés disso, ele corresponde a uma prova por indução. (PR, \$189) 
Naturalmente, Wittgenstein não era estúpido a ponto de negar ao Teorema Fundamental da Álgebra (ou ao Último Teorema de Fermat, caso houvesse uma prova desse teorema naquele tempo) o estatuto de teorema. Acontece apenas que ele nega que qualquer um dos dois seja uma "proposição", no sentido que ele dá a esta palavra no Tractatus, simplesmente porque eles são provados - e, como ainda não tinham sido provados, ${ }^{54}$ deveríamos dizer, ao invés disso: porque eles deveriam ser provados - recursivamente. Portanto, à luz do raciocínio que acabamos de fazer, eles não são semelhantes a sentenças com quantificadores.

Estamos nos enredando, aqui, com a Lei do Terceiro Excluído, e vale a pena aprofundar este assunto, pois isto porá em evidência um ponto importante para a interpretação de Wittgenstein. Como ele mesmo reparou:

Nem é preciso dizer que, onde a lei do terceiro excluído não se aplica, nenhuma outra lei da lógica se aplica, pois nesse caso não estaremos lidando com proposições da matemática. (Contra Weyl e Brouwer.) (PR, \$151)

Se a lei do terceiro excluído não se aplica, isto quer dizer que nossa expressão não é comparável a uma proposição. (BT, p. 448) (PG, p. 400)

O resultado líquido de tudo isto é que a Lei do Terceiro Excluído, como qualquer outra coisa que mereça o nome de lógica, não se aplica em contextos nos quais não existam proposições no sentido do Tractatus, mas apenas fórmulas com variáveis livres. Poderíamos também descrever esse resultado líquido dizendo que Wittgenstein e Goodstein vão mais longe que os intuicionistas (isto é, Brouwer e Weyl, mencionados na citação que fizemos há pouco), pois afastam definitivamente a teoria da quantificação e restringem o cálculo equacional a domínios que parecem ser decidíveis, aos quais a Lei do Terceiro Excluído se aplica. Por esta razão, tanto Wittgenstein quanto Goodstein tinham uma atitude ambivalente com relação à crítica feita por Brouwer da Lei do Terceiro Excluído. Brouwer disse apenas que deveríamos evitar a aplicação da Lei do Terceiro excluído em certos contextos. Wittgenstein e Goodstein não eram desta opinião, pois suas críticas à teoria da quantificação eram mais radicais. Assim, eles tiveram de rejeitar a crítica de Brouwer por suas insuficiências. Por exemplo, Goodstein abre o seu Constructive Formalism da seguinte maneira: 
Wittgenstein mostrou que, numa linguagem formal, o significado dos sinais é uma propriedade puramente funcional da linguagem. Segue-se daí que Brouwer estava totalmente equivocado quando negou a validade de um axioma formal - o tertium non datur. (GOODSTEIN, 1951, p. 9)

E, em sua aula inaugural, ele declarou que

A rejeição por Brouwer do tertium non datur deve ser considerada um equívoco completo. (GOODSTEIN, 1959, p. 16)

Wittgenstein também criticou Brouwer por oferecer o tipo errado de argumento contra a Lei do Terceiro Excluído, p.ex. (BT, p. 487) (PG, p. 458). Infelizmente, costuma-se interpretar comentários deste tipo como uma defesa da Lei do Terceiro Excluído, e como prova de que Wittgenstein não tinha qualquer inclinação construtivista. Não irei mostrar aqui que isto é uma interpretação completamente inadequada das observações de Wittgenstein. ${ }^{55}$ No entanto, a reconstrução que estou fazendo aqui dos vínculos estreitos existentes entre Wittgenstein e o cálculo equacional de Goodstein fornece o pano de fundo a partir do qual poderíamos interpretar de modo frutífero as observações de Wittgenstein a respeito da crítica feita por Brouwer da Lei do Terceiro Excluído e de outros aspectos do intuicionismo. Portanto, talvez valha a pena contar uma ou duas coisas a respeito do ponto de vista do próprio Goodstein, já que esse ponto de vista é pouquíssimo conhecido.

Como questão de fato, Goodstein concordava com Brouwer que o seguinte deveria ser rejeitado: ${ }^{56}$

$\neg \forall x F(x) \rightarrow \exists x \neg F(x)$

Pelo que vimos até aqui, Wittgenstein e Goodstein raciocinavam da seguinte maneira: pode-se ter uma prova recursiva e associar a ela um enunciado universal, como “ $\neg \forall x F(x)$ ”. Ao passo que eles tentavam mostrar que, se olharmos para a prova, veremos que ela não prova o enunciado universal, outros não concordavam com isto e usavam o condicional acima para inferir também que " $\exists x \neg F x$ ". Este último passo não poderia de maneira alguma ser justificado do ponto de vista de Wittgenstein e Goodstein. Deve-se notar o quanto o raciocínio, neste 


\section{8}

ponto, aproxima-se do de Brouwer: 57 segundo ele, inferir " $\exists x \neg F x$ " a partir de “ $\neg \forall x F(x)$ " é ilegítimo, pois esta última sentença é uma expressão das construções mentais do matemático, ao passo que a inferência que nos leva a " $\exists x \neg F x$ " - legítima, se sustentamos a Lei do Terceiro Excluído - é ilegítima neste caso, pois o matemático não forneceu (e, em alguns casos, não poderia fornecer) nenhuma construção. Não podemos, a partir da prova, exibir um a tal que $\neg F$ a. A única diferença, neste caso, é que Brouwer expressou o argumento em termos de construções mentais feitas pelo matemático (e somos todos filósofos esclarecidos que consideraríamos isto inaceitável, não somos?), ao passo que Wittgenstein e Goodstein expressaram-no em termos de uma análise daquilo que uma prova recursiva mostra, mas não pode, ela mesma, dizer. Se não entendermos isto, penso que nem sequer começamos a entender qualquer coisa a respeito daquilo que Wittgenstein quis dizer a respeito do "unheilvolle Einbruch" da matemática pela lógica (RFM, V, \$46). No que diz respeito a Goodstein, ele estava condenado a compartilhar o ponto de vista de Brouwer, quando não a sua linguagem. E, exatamente como Brouwer, Goodstein usou contraexemplos mostrando que a impossibilidade da não existência não implica existência. $\mathrm{O}$ argumento favorito de Goodstein é muito bom, e envolve a conjectura de Goldbach, segundo a qual "todo número par maior que 2 é a soma de dois primos", e um teorema básico da análise, devido a Weierstrass, segundo o qual "qualquer sequência não decrescente limitada superiormente converge para um único limite" (GOODSTEIN, 1965, p. 3-4 \& 97-98). 58 Este último é um "teorema de existência" provado por reductio ad absurdum. Goodstein sugeriu que apliquemos este teorema a uma sequência $a_{\mathrm{n}}$, para $\mathrm{n} \geq 1$, definida da seguinte forma:

$a_{\mathrm{n}}=0$, caso todo número par de 2 até $2 n$ seja a soma de dois primos.

$a_{\mathrm{n}}=1$, caso ocorra o contrário.

Esta sequência é não decrescente: se $a_{\mathrm{n}}=1$ para algum $n$, então um dos números pares de 2 até $2 n$ não é a soma de dois números primos e, desse modo, $a_{\mathrm{m}}=1$ para $m \geq n$. Ela é limitada, pois cada um de seus termos é ou 0 , ou 1. Assim, de acordo com o teorema da existência, ela possui um limite. Mas qual? 0 ou 1? Como sabemos que a conjectura de Goldbach vale para todos os números testados até agora, podemos afirmar que a 
sequência começa com um determinado número de zeros. Se todo termo é 0 , então o limite é 0 , mas se houver um contraexemplo à conjectura de Goldbach, então um termo será 1 e, portanto, todos os termos subsequentes também serão, e, portanto, o limite será 1 . Noutras palavras, se a conjectura de Goldbach é verdadeira, o limite é 0; se não for, é 1. Estamos, portanto, diante de uma situação na qual uma sequência definida possui um limite, mas não sabemos qual. Goodstein considerava essa situação simplesmente inaceitável. Há muito pouca coisa aqui para distinguir a crítica de Goodstein da de Brouwer, mas ele comentou:

Foi para proteger a matemática de resultados estéreis como este [o exemplo que Goodstein apresenta neste ponto é análogo àquele que acabamos de examinar] que Brouwer rejeitou o tertium non datur. $\mathrm{O}$ mesmo objetivo, no entanto, pode ser atingido de outras maneiras. Poderíamos, por exemplo, reter o tertium non datur, mas excluir qualquer afirmação pura e simples de existência, prática restritiva que é conhecida como finitismo em matemática, pois seu efeito é permitir a aplicação do tertium non datur apenas àqueles casos nos quais as alternativas podem ser testadas num número finito de passos. O finitista rejeita a afirmação pura e simples de existência porque ela é uma infinidade de disjunções, e ele sustenta que seria uma contradição em termos falar em teste de um número infinito de casos. (GOODSTEIN, 1959 , p. 11) $)^{59}$

E Goodstein também tentou mostrar, por analogia, que deveríamos rejeitar a outra implicação constitutiva da teoria da quantificação: 60

$\neg \exists x F(x) \rightarrow \forall x \neg F(x)$

isto é, que a impossibilidade de um contraexemplo garanta a universalidade. Mais uma vez, vale a pena citá-lo:

Parece-me que este princípio também é questionável. Como ele estabelece $\forall x P(x)$ para mostrar que a hipótese da existência de um contraexemplo leva à contradição? Presumivelmente, vamos testando $\mathrm{P}(0), \mathrm{P}(1), \mathrm{P}(2), \ldots$ sem encontrar um único contraexemplo. Provamos, então, que, se por acaso tivéssemos encontrado um contraexemplo, teríamos encontrado uma contradição (na aritmética), e concluímos daí que $\forall x P(x)$. Na falta de uma prova de ausência de contradição, o 
argumento é pouco mais do que uma expressão de fé na consistência. (GOODSTEIN, 1965, p. 107)

Pode-se perceber, eu espero, que as palavras duras que Goodstein dirige contra a crítica que Brouwer faz da Lei do Terceiro Excluído não são as de um reacionário, pronto a defender a lógica clássica contra críticas descabidas. ${ }^{61}$ Ele defende, na verdade, um ponto de vista ainda mais radical que o de Brouwer.

Não há em Wittgenstein argumentos equivalentes aos que acabamos de apresentar. No entanto, a alegação de que uma lei como (A) não possui um contraditório e não pode ser negada é repetida à exaustão no Big Typescript, como já vimos. Wittgenstein também usa mais de uma vez o famoso exemplo de Brouwer envolvendo a ocorrência da sequência '7777777' na expansão decimal de $\pi$ para estabelecer exatamente a mesma tese. O próprio Goodstein menciona Brouwer e Wittgenstein na mesma sentença:

Considere o problema de que Brouwer lançou mão diversas vezes, de saber se na expansão decimal de $\pi$ o 7 ocorre sete vezes consecutivas. A expansão com $10^{10}$ algarismos já existe antes mesmo de ter sido calculada? Como observou Wittgenstein, será que um personagem já existe antes mesmo de a peça em que ele aparece ter sido escrita? Se, como podemos supor, o único método de abordar o problema é calcular a expansão de $\pi$, então é impossível provar que uma sequência de sete 7's não ocorre. A situação não melhora pelo fato de abordarmos o problema utilizando todos os recursos da matemática contemporânea, pois nesse caso teremos apenas substituído a questão de saber se os sete 7's ocorrem numa certa expansão pela questão similar de saber se certa sentença ocorre ou não na infinita cadeia de inferências que podemos extrair de nosso conhecimento atual. (GOODSTEIN 1965, p. 98-99)62

Considere, por exemplo, esta observação de Wittgenstein: ${ }^{63}$

Não é possível fazer uma pergunta como esta: Os algarismos $0,1,2, \ldots$, 9 ocorrem em $\pi$ ? Eu só posso perguntar se eles ocorrem em um ponto determinado, ou então se eles ocorrem entre os primeiros $10 \mathrm{mil}$ algarismos. Nenhuma expansão, por mais longe que vá, pode refutar a afirmação "Eles ocorrem". Portanto, esta afirmação também não pode 
ser verificada. O que verificamos é uma asserção completamente diversa, a saber, que esta sequência ocorre neste ou naquele ponto. Seguese daí que não se pode afirmar ou negar esse enunciado e, portanto, não se pode aplicar a ele a lei do terceiro excluído.

(WITTGENSTEIN, 1979b, p. 71)

O que eu pretendo mostrar aqui é simplesmente que o ponto de vista radical a partir do qual Goodstein critica a teoria da quantificação e a partir do qual Brouwer faz sua crítica pela metade é também o ponto de vista de Wittgenstein. ${ }^{64}$ Mesmo considerando que Goodstein elaborou esta crítica muito mais extensamente que Wittgenstein, e mesmo considerando que Wittgenstein, por tudo que sabemos, talvez não tivesse aprovado alguns de seus desdobramentos, parece inegável que ambos compartilhavam esta rejeição da teoria da quantificação, que os argumentos de Wittgenstein correm então paralelamente aos de Goodstein e que, portanto, não é possível interpretar Wittgenstein se não estivermos prontos a reconhecer este comprometimento.

\section{Observações finais}

Para concluir, eu gostaria de retornar ao "Novo Wittgenstein". É bastante claro que, após seu regresso em 1929 a Cambridge e aos estudos filosóficos, Wittgenstein retomou a reflexão a respeito de temas que estariam no interior da "moldura" do Tractatus. Portanto, ou devemos supor que o Wittgenstein $_{\mathrm{A}}$ de algum modo teve uma recaída no Wittgenstein ${ }_{\mathrm{CS}}$ durante o período intermediário, ou então devemos deixar definitivamente de lado essa suposta esquizofrenia separando Wittgenstein ${ }_{\mathrm{A}}$ de Wittgenstein $\mathrm{CS}_{\mathrm{CS}}$. A distinção entre mostrar e dizer é um alvo privilegiado para os leitores "resolutos" do Tractatus, já que a tese central em torno da qual se organiza sua leitura consiste em negar que haja qualquer sentido na idéia de que algumas proposições seriam capazes de mostrar algo que elas não podem dizer. $\mathrm{Na}$ leitura deles, isto seria apenas mais uma das coisas que deveríamos abandonar quando jogarmos fora a escada.Vimos que essa distinção, no entanto, está no coração mesmo da explicação da aritmética por Wittgenstein,já que esta última é uma forma de teoria no plano daquilo que se mostra em 


\section{2}

um cálculo equacional, a ser distinguido de um cálculo lógico que só se aplicaria às "proposições". Mas, será que isto tudo não passa de ilusão? Isto equivaleria a dizer que Wittgenstein ${ }_{\mathrm{A}}$ não apenas queria criticar o logicismo de Frege e Russell como um contra-senso puro e simples, mas também alegar que sua própria alternativa, construída para criticar a deles, é ela também tão carente de sentido quanto a deles. Que sentido teria, nesse caso, tentar solapar seus próprios argumentos? E se, no que diz respeito aos fundamentos da matemática, o ponto central do livro é mostrar que os filósofos não deveriam se envolver nesse assunto (a matemática está muito bem do jeito que está, etc.), então temos o direito de indagar se uma linha de raciocínio autodestrutiva seria a melhor estratégia para estabelecer esse ponto. $\mathrm{O}$ que equivale a dizer que não se tem, aqui, argumentos - e, nesse caso, pode-se muito bem expressar sua opinião e depois calar-se, deixando os outros fazerem o seu trabalho em paz.

Há também o problema de suas outras reflexões durante o período intermediário, que o levaram inter alia a substituir a indução pela unicidade no Big Typescript. Tendo-se em vista as conexões que procurei traçar, isto equivaleria a pensar que o cálculo equacional de Goodstein e as observações de Wittgenstein no Big Typescript são "contra-sensos genuínos”. Quer sejam, quer não, tudo aquilo que está no interior da moldura do Tractatus certamente o é, e isto traz uma série de problemas para qualquer leitura "resoluta". A verdade, porém, é que nem o cálculo equacional de Goodstein, nem as observações de Wittgenstein no Big Typescript podem ser classificados como contra-sensos, a não ser que se queira logo de cara lançar um insulto aos matemáticos. Se isto é tudo que a filosofia tem a fazer, então ela é verdadeiramente uma empreitada estúpida e uma perda de tempo. Ao responder a seus críticos, quando estes apontam para o enorme peso da evidência "externa”, isto é, para passagens posteriores ao Tractatus que atacam suas próprias teses mostrando quais eram os compromissos metafísicos daquele livro, os leitores "resolutos" respondem que estes talvez fossem compromissos não intencionais, que mais tarde foram reconhecidos por Wittgenstein enquanto tais. ${ }^{65}$ Não me parece que essa resposta possa funcionar neste caso, pois há claramente uma preocupação em resolver problemas deixados em aberto no Tractatus seguindo sua estratégia geral, que era a de fornecer uma abordagem da aritmética (estendendo-a para os números reais - algo 
sobre o que não tenho como falar aqui) em termos de um cálculo equacional. Não existe vestígio de qualquer tentativa de diagnosticar compromissos não intencionais, ou coisas desse gênero. ${ }^{66}$

Concluo a partir disso tudo que as reflexões de Wittgenstein a respeito dessa espécie de cálculo equacional que encontramos no Tractatus mostram (sem querer fazer trocadilhos) que ele certamente não considerava a distinção entre mostrar e dizer como sendo, ela própria, um contrassenso, pois supor isto seria admitir que toda a sua abordagem da matemática em termos da teoria das operações e, por extensão, o cálculo equacional de Goodstein, é simplesmente um contrassenso. É claro que isto é apenas um argumento, e não pretendo decidir o debate por meio dele. Estou apenas tentando mostrar que as observações $6.02-6.031$ e 6.2 - 6.241 têm que ser enfrentadas de algum modo pelos leitores "resolutos". Se, por outros motivos, uma leitura "resoluta" deve ser preferida por exemplo, por seu anti-realismo em relação à necessidade, com o qual eu simpatizo - quanto dessa leitura é realmente compatível com a abordagem wittgensteiniana da aritmética que acabo de descrever? Eu não me aventuraria a dar uma resposta neste estágio.

Reservei para minhas observações finais uma passagem do ensaio de Goodstein “Wittgenstein's Philosophy of Mathematics":

Devemos admitir que a crítica que Wittgenstein faz da indução matemática é muito mais uma crítica da linguagem na qual o método era tradicionalmente apresentado, do que do próprio método.

(GOODSTEIN, 1972, p. 281-282)

É claro que Goodstein estava certo ao fazer esta observação, e ela sozinha deveria suavizar grande parte do drama associado à possibilidade de Wittgenstein ter "tomado posição", ou seja, de ter defendido posições "construtivistas", ou de ter se "imiscuído" no trabalho dos matemáticos, dizendo-lhes que tal e tal resultado não deveria valer (tal como fazem alguns construtivistas). O próprio Wittgenstein escreveu:

A filosofia não examina os cálculos dos matemáticos, mas apenas o que os matemáticos dizem a respeito desses cálculos. (BT, p. 444) (PG, p. 396)

E num certo sentido estas derivações deixaram tudo como estava. (BT, p. 460) (PG, p. 420) 


\section{4}

Deve-se notar que Goodstein não compartilha esta opinião. Ele concluiu sua aula inaugural (1951) com as seguintes palavras:

A menos que venhamos a descobrir alguma reinterpretação finitista de sistemas não construtivos comparável à reinterpretação da análise clássica que se tenta fazer na teoria das funções recursivas, uma parte considerável do amplo espectro de desenvolvimentos modernos da matemática deve ser considerada carente de significação, ou então totalmente desprovida de fundamentação. (GOODSTEIN, 1959, p. 25)

É claro que Wittgenstein pode estar errado quando diz que seus comentários críticos "deixam tudo como está". Isso, no entanto, é algo que aqueles que se especializaram em fundamentos da matemática devem nos dizer, já que a maioria dos comentadores de Wittgenstein simplesmente não tem competência para avaliar esse tipo de questão, e deveriam em função disso mostrar um pouco mais de modéstia. Esses mesmos comentadores, no entanto, deveriam notar que as observações acima, muito conhecidas por sua ocorrência noutro contexto, ${ }^{67}$ também ocorrem em meio à discussão a respeito das provas recursivas no Big Typescript, onde é claro que seu sentido está entrelaçado com a aplicação da distinção entre mostrar e dizer à distinção entre uma prova recursiva e a sentença universalmente quantificada que supostamente captura aquilo que a prova havia mostrado. Ao separar uma da outra, estamos a um só tempo criticando a maneira de falar de alguns matemáticos, e deixando os cálculos intocados. Wittgenstein critica a linguagem na qual nós tradicionalmente falamos a respeito da indução matemática, e o que essa crítica nos mostra é que ele via nessa linguagem uma fonte de erros filosóficos, e não uma tentativa de reconstruir a matemática a partir destes ou daqueles "fundamentos", fossem eles mais estreitos ou não. (É pelo menos esta a crença que ele expressa com toda a clareza em BT, p. 460 - 461. Uma vez mais, cabe aos especialistas avaliarem o verdadeiro impacto de suas idéias.) Uma grande quantidade de wittgensteinianos - eu diria mesmo uma quantidade excessiva - parecem obcecados pela possibilidade de lhe atribuir algum rótulo, algum "ismo", como "finitismo", o que o deixaria imediatamente exposto a críticas. Isto é mais uma reflexão a respeito deles do que a respeito de Wittgenstein. A meu ver, sua crítica da indução exemplifica bem o tipo de resultado que ele desejava obter em filosofia - um tipo de 
resultado para o qual inúmeras pessoas (aí incluídos muitos de seus fãs) mostram-se musicalmente surdas, de tal modo que eu temo que as condições necessárias para uma avaliação apropriada de suas idéias ainda não estejam dadas. Não consigo, porém, ver de que maneira seria possível desencavar a fonte dos erros filosóficos nos fundamentos da matemática sem nenhum tipo de compromisso - parece-me que nada seria dado de bandeja, neste caso, especialmente se vier acompanhado de um argumento que se autorrefuta. Os que temem a atribuição de qualquer compromisso a Wittgenstein, e que gostariam, em função disso, de classificar tudo que eu disse aqui como contra-senso puro e simples (ou então como erro de interpretação), estão, portanto, jogando o bebê junto com a água do banho. Se Wittgenstein tem qualquer interesse, isto se dá porque suas observações têm interesse.

${ }^{1}$ Devo a ROSE 1988 os dados biográficos (e bibliográficos) a respeito de Goodstein.

2 Os exames finais (feitos em duas etapas) para a obtenção do título de Bachelor of Arts em matemática. [N.T.]

3 Master of Science. [N.T.]

${ }^{4}$ Este não é o lugar adequado para darmos uma descrição desse belo teorema. Cf., por exemplo, SMITH, 2007, p. 201-204.

5 Este resultado foi obtido após uma prova elaborada por Jeff Paris e Leo Harrington de que uma versão mais forte da porção finita do Teorema de Ramsey que pode ser enunciada na linguagem da aritmética elementar não pode ser provada na aritmética de Peano de primeira ordem (PARIS \& HARRINGTON, 1977). A ideia que está por trás desse resultado é que o teorema da incompletude de Gödel envolveria um enunciado "feito sob medida", que dificilmente tem qualquer sentido aritmético e que, portanto, é preciso encontrar um enunciado desse tipo, isto é, uma verdade aritmética que possamos demonstrar que não pode ser provada na aritmética de Peano de primeira ordem. Pode-se argumentar, como faz por exemplo SMITH, 2007, p. 201, que o Teorema de Goodstein é um candidato mais interessante, desse ponto de vista, do que a versão da parte finita do Teorema de Ramsey, que fora usada por Paris e Harrington.

${ }^{6}$ A história está contada em MONK, 1990, p. 336. Antes de sua morte prematura, Skinner tornou-se amigo íntimo de Wittgenstein. Sua amizade com Goodstein vinha desde a escola secundária, no colégio de São Paulo, em Londres. As notas tomadas por Alice Ambrose das poucas aulas dadas no curso de "Filosofia para Matemáticos" estão disponíveis em WITTGENSTEIN, 1979a, p. 203-225.

doispontos, Curitiba, São Carlos, vol. 6, n. 1, p.195-246, abril, 2009 


\section{6}

7 Por outro lado, devo declarar que Georg Henrik von Wright contou-me certa vez, numa conversa, que, assim que ele chegou a Cambridge, em 1939, Wittgenstein falou mal do artigo de Goodstein. Achava que o artigo de Alistair Watson, "Mathematics and its Foundations", publicado no ano anterior, era muito melhor (WATSON, 1938). No entanto, segundo von Wright, as críticas de Wittgenstein a Goodstein não eram tão negativas quando as que ele fazia ao artigo de Alice Ambrose, de 1935 (AMBROSE, 1935). Por isso, penso que deveríamos tomar cuidado antes de usar o testemunho de von Wright como razão para desqualificar Goodstein como mais um daqueles cérebros menores que não conseguiram compreender o gênio - uma atitude patética, mas não muito infrequente, em especial quando se faz referência ao artigo de Ambrose. Ela me disse em particular que, mesmo após conversar durante muitas horas com Wittgenstein, nunca foi capaz de entender exatamente o que ele desaprovava em seu artigo.

8 Dada a natureza "finitista" da obra madura de Goodstein, é razoável perguntar que relação poderia haver entre ela e seus trabalhos iniciais em torno do teorema ordinal restrito. À primeira vista, parece não haver relação nenhuma. Não devemos nos esquecer, porém, de que Goodstein nunca rejeitou a indução transfinita até $\varepsilon_{0}$, que ele encarava como "um desvio absolutamente mínimo" de uma perspectiva puramente finitista (GOODSTEIN, 1959, p. 15). De mais a mais, ele mostrou em (GOODSTEIN, 1944) que o "teorema ordinal restrito" para ordinais menores que $\varepsilon_{0}$ é demonstrável na aritmética recursiva. (Para um comentário adicional a respeito disto, cf. a nota 14 abaixo.) Deve-se notar, além disso, que o divisor de águas parece se dar em torno da "conjectura de Isaacson", isto é, da alegação de que "se quisermos dar uma demonstração racionalmente cogente de qualquer sentença verdadeira da linguagem da aritmética elementar que seja independente da aritmética de Peano, teremos de fazer apelo a ideias que ultrapassam o âmbito daquelas que são constitutivas de nosso entendimento da aritmética básica". (Esta é uma versão ligeiramente modificada daquela que pode ser encontrada em SMITH, 2007, p. 205; para a formulação e a motivação originais, cf. ISAACSON, 1996.) Tem-se a impressão de que a obra madura de Goodstein consiste principalmente numa estratégia para evitar qualquer apelo a ideias (lógicas, conjuntistas) que não sejam "constitutivas de nosso entendimento da aritmética básica". O que isto significa exatamente é algo que permanece obscuro. Em todo caso, somos levados a pensar que Goodstein estava tentando esclarecer isso para si mesmo no curso de suas reflexões a respeito da necessidade de substituir a indução pela unicidade.

${ }^{9} \mathrm{O}$ finado Robin Gandy, que conseguiu seu primeiro posto em Leicester nos anos 50 com a ajuda de Goodstein, contou-me que, naquele tempo, Goodstein continuava referindo-se a Wittgenstein em discussões e nas aulas. Infelizmente, Gandy, que na época provavelmente não percebeu o quão preciosas eram essas observações, não foi capaz de recordar nada de mais específico.

10 Embora o artigo de Goodstein tenha sido publicado em 1945, ele foi escrito na mesma época que o de Curry, em 1940. Cf. GOODSTEIN, 1959, p. 17.

$11 \mathrm{Um}$ aperfeiçoamento indo nessa mesma direção pode ser encontrado em GOODSTEIN, 1954.

12 Na mesma nota de rodapé, Goodstein também atribui a substituição da indução matemática por uma regra de unicidade a Paul Bernays. Infelizmente, Goodstein, usualmente tão 
meticuloso em suas referências, não fornece nenhuma neste caso, e é possível que ele se baseie apenas em alguma conversação ou correspondência com Bernays. Richard Zach me disse que há inúmeras cartas trocadas entre eles no começo dos anos 40 depositadas na coleção de documentos de Bernays na ETH (Eidgenössische Technische Hochschule), em Zürich. Ainda não pude consultá-la. Em todo caso, eu certamente não estou alegando que Wittgenstein teria qualquer prioridade neste caso.

13 Sobre Kronecker, cf. MARION, 1995b, muito embora eu não acredite que o ponto de vista de Kronecker se reduza a esta porção de seu legado. Quanto a Skolem, cf. SKOLEM, 1967. Para um breve apanhado histórico do construtivismo que insere a obra de Goodstein nessa tradição, cf.TROELSTRA \& van DALEN, 1988, p. 25.

14 Esta não é a única reclamação. Os escritos de Goodstein estão maculados por algum desleixo notacional, e suas ideias são com frequência pouco claras. Assim, por exemplo, Goodstein define seu ponto de vista como sendo um meio termo entre a recursividade primitiva e a geral - a primeira seria muito restrita, e a segunda excessivamente ampla. Ele descrevia seu ponto de vista nos seguintes termos: "Caso seu ordinal seja menor que $\varepsilon_{0}$, as funções primitivas recursivas transfinitas têm um caráter tão estritamente finitista quanto o das funções recursivas primitivas. No entanto, caso seu ordinal seja $\varepsilon_{0}$, para provar que os valores de uma função recursiva transfinita podem ser determinados num número finito de passos, nós temos que recorrer ao teorema ordinal restrito para ordinais menores ou iguais a $\varepsilon_{0}$. Parece-me, portanto, que, na sucessão sem fim de funções recursivas transfinitas cujo ordinal é menor que $\varepsilon_{0}$, nós atingimos o limite da definição demonstravelmente recursiva" (GOODSTEIN, 1959, p. 18). (Corrigi o texto todo, que fala apenas em " $E$ ".) De certo modo, isto é tecnicamente incorreto, quando por mais não seja, porque podemos obter todas as funções gerais recursivas fazendo apelo somente ao ordinal $\omega$.

15 Sobre a sub-recursão, cf. ROSE, 1984.

16 Um artigo fundamental, SIMPSON, 1988, foi publicado no mesmo ano que o obituário de Rose.

17 Para um exemplo recente de comentários que foram escritos sem levar em conta estes pontos, e que portanto devemos em larga medida desconsiderar, por fazerem uma leitura pobre, cf. PUTNAM, 2007. O resultado das relações que estabeleço aqui é mostrar que a filosofia da matemática de Wittgenstein não pode ser simplesmente descartada como se fosse um "lixo" - não mais, pelo menos, do que as perspectivas filosóficas de Skolem ou de Goodstein, ou do que os desenvolvimentos matemáticos que sustentam essas perspectivas. Pode-se não compartilhar a mesma perspectiva, mas ela não é um "lixo".

${ }^{18}$ Veja-se, por exemplo, no quadro geral daquilo que vem exposto em LAMBEK \& SCOTT, 1986, as reformulações ulteriores da regra da unicidade que aparecem em LAMBEK, 1988 e em ROMAN, 1989. Estes desenvolvimentos são brevemente apresentados em OKADA, 2007, p. $128-130$.

19 De acordo com aquilo que vem dito na introdução de CRARY \& READ, 2000, a expressão "Novo Wittgenstein" deveria abranger mais do que a leitura do Tractatus iniciada por Cora Diamond, mas isto não tem muita importância para o que vem a seguir. O nome torna-se ridículo principalmente porque este ponto de vista exegético não poderia 


\section{8}

permanecer "novo" para sempre e, de qualquer forma, não havia nada de propriamente novo na recauchutagem de ideias já defendidas anteriormente por Rush Rhees e Oets Bouwsma. Trata-se, antes, de um debate perene entre os especialistas em Wittgenstein, debate no qual uma das correntes ganhou maior notoriedade nos últimos tempos.

20 Cf. CONANT, 1989, p. 274, n. 16, para a alegação de que as observações com "sentido" resumem-se apenas a 6.54 .

$21 \mathrm{Na}$ Rússia, o termo designava um pronunciamento do tzar que tinha força de lei. [N.T]

22 Naturalmente, estes não são os únicos lugares em que podemos encontrar esta mesma alegação. Cf., por exemplo, CONANT \& DIAMOND, 2004, p. 48.

23 Esta expressão provém de GOLDFARB, 1997, p. 64.

24 Poema nonsense que Lewis Carroll insere no livro Through the Looking-Glass, and What Alice Found There [N.T.].

25 Cf. SULLIVAN, 2003, p. 196.

26 Este ponto é lembrado em HACKER, 2000, p. 360.

27 Cf., por exemplo, CONANT, 1993.

28 Se alguém pensa que estou sendo burlesco e portanto injusto, por favor, leia CONANT, 1993, p. 216. Para "leitores resolutos", o corpo do Tractatus é composto por "sequências gramaticalmente bem formadas de palavras que ressoam com uma aura de sentido".

29 Ao menos para leitores como FRASCOLLA, 1994, cap. 1, MARION, 1998, cap. 2 e POTTER, 2000, cap. 6.

${ }^{30}$ Wittgenstein $_{C S}$ fala apenas a respeito da aritmética e, por isso, de agora em diante pararei de falar da matemática em geral. As consequências que esta restrição tem sobre nossa avaliação de seus pontos de vista não serão discutidas aqui.

31 Pode-se questionar se $a$ deve ou não ser uma "proposição". Novamente, não entraremos aqui no mérito destas questões.

32 Seguindo a sugestão de POTTER, 2000, p. 184.

33 Novamente, seguindo POTTER, 2000, p. 184.

34 Esta idéia foi expressa primeiramente em FRASCOLLA, 1994, p. 3. Também pode ser encontrada em MARION, 1998, p. 26, e POTTER, 2000, p. 182.

35 Cf. FRASCOLLA, 1994, p. 18-19, para um exemplo completamente desenvolvido numa notação diferente, mas mais precisa.

36 A fórmula está baseada em $\star 54.43$, e foi escolhida simplesmente em função do papel que ela desempenhará na terceira parte das Observações sobre os Fundamentos da Matemática (RFM) de Wittgenstein. Ela mostra a continuidade das preocupações de Wittgenstein.

$37 \mathrm{Na}$ verdade, pode-se obter a lógica a partir da aritmética. Por exemplo, pode-se escrever a conjunção $A=0 \& B=0$ no lugar de $A+B=0$, já que é possível derivar tanto $A=0$ quanto $B=0$ a partir de $A+B=0$. Não poderei mostrar isso aqui, mas Goodstein tem condições de fornecer,

doispontos, Curitiba, São Carlos, vol. 6, n. 1, p.195-246, abril, 2009 
no cálculo equacional, equivalentes dos axiomas dos Principia Mathematica (por exemplo), provando-os dentro de seu sistema.

38 Há algumas razões bastante boas para que Wittgenstein quisesse proceder assim. Fiel à estratégia que admirava em Herz, ele dissolveria as dificuldades apresentadas pela abordagem da aritmética na teoria (ramificada) dos tipos dos Principia Mathematica separando primeiramente a aritmética da lógica, e então fornecendo uma abordagem alternativa (baseada na teoria livre-de-lógica das operações).

39 A respeito do "impensável” no Tractatus, cf. 4.123.

40 Como vem assinalado em POTTER, 2000, p. 183.

${ }^{41}$ A única exceção é MARION, 1998, p. 101.

42 O capítulo é reproduzido quase verbatim na Gramática Filosófica, Parte II, capítuloVI, seções 29-38. No que se segue, acrescentarei às minhas citações do Big Typpescript referências às passagens correspondentes da Gramática Filosófica.

43 Esta é uma versão ligeiramente modificada de SKOLEM, 1967, p. 305-306.

44 Deixarei de lado a distinção esquizofrênica entre Wittgenstein ${ }_{A}$ e Wittgenstein ${ }_{C S}$ daqui por diante, já que estamos fora do âmbito do Tractatus e até agora não foram feitas "regras de leitura" para o período intermediário.

45 Mesmo não sendo imediatamente relevante, vale a pena citar o restante da passagem: "Não estamos dizendo que, se temos $\mathrm{f}(1)$ e se $\mathrm{f}(\mathrm{c}+1)$ segue-se de $\mathrm{f}(\mathrm{c})$, a proposição $\mathrm{f}(\mathrm{x})$ é verdadeira de todos os números cardinais. Estamos dizendo o seguinte: 'A proposição $\mathrm{f}(\mathrm{x})$ vale para todos os números cardinais' significa 'Ela vale para $\mathrm{x}=1$, e $\mathrm{f}(\mathrm{c}+1)$ segue-se de $\mathrm{f}(\mathrm{c})$ '. E, aqui, a conexão com a generalidade em domínios finitos é bastante clara, pois num domínio finito aquilo mesmo seria uma prova de que $\mathrm{f}(\mathrm{x})$ vale para todos os valores de $\mathrm{x}$, e é exatamente essa a razão pela qual, também no caso da aritmética, dizemos que $\mathrm{f}(\mathrm{x})$ vale para todos os números." (BT, p. 453) (PG, p. 406).

46 Cf. OKADA, 2007, p. 123.

47 Sigo sem maiores modificações a apresentação que pode ser encontrada em GOODSTEIN, 1972, p. 280-281.

48 Cf. também BT, p. 457 \& 462, PG, p. 409 \& 414.

49 Segundo Okada, temos aqui uma importante diferença em relação ao finitismo de Hilbert (OKADA, 2007, p. 127-128). Na verdade, Hilbert acreditava que, para recuperar (as leis da lógica clássica para), digamos,

$a+(b+1)=(a+b)+1$

deveríamos acrescentar às "proposições reais", como

$2+(3+4)=(2+3)+4$

e às "proposições finitárias gerais", como

$x+(y+1)=(x+y)+1$

algumas "proposições ideais", como

$\forall x \forall y x+(y+1)=(x+y)+1$

doispontos, Curitiba, São Carlos, vol. 6, n. 1, p.195-246, abril, 2009 


\section{0}

Este acréscimo era concebido em termos de uma prova de consistência que, como diz Okada, tinha também a função de conectar duas "gramáticas" - a gramática das proposições reais e das proposições gerais finitárias, tomadas conjuntamente, e a gramática das proposições ideais. Esta conexão deveria ocorrer por meio de uma prova de consistência elaborada na linguagem da primeira gramática. Para Wittgenstein, porém, a conexão era apenas mostrada.

50 Literalmente, “cálculo com letras” [N.T.].

51 Cf. MARION, 1998, p. 98.

52 Bem, nas palavras de Goodstein: “A falta de quantificadores, na verdade, não protege a aritmética recursiva contra a construção das fórmulas indecidíveis de Gödel. No entanto, a impossibilidade de uma prova intrínseca de consistência não é uma fraqueza num sistema de variáveis livres que é completamente verificável.” (GOODSTEIN, 1959, p. 17)

53 Mas veja: Bundy foi aluno de Goodstein!

54 Goodstein apresenta uma prova do teorema fundamental da álgebra em GOODSTEIN, 1969.

55 Discuti meticulosamente a relação entre Brouwer e Wittgenstein em MARION, 2003 e MARION, 2008.

56 Por exemplo, em GOODSTEIN, 1959, p. 20.

57 A melhor formulação continua sendo aquela que encontramos no artigo original de Brouwer, de 1908, “The Unreliability of the Logical Principles" (BROUWER, 1975, p. 1, 107-111), mas pode-se encontrar a mesma opinião expressa na conferência feita em 1928, em Viena, assistida por Wittgenstein, que posteriormente passaria um dia todo discutindo com Brouwer. Cf. MARION, 2003 e MARION, 2008 a respeito desta última afirmação.

58 Cf. também GOODSTEIN, 1951, p. 43.

59 Para uma discussão completa deste assunto, remeto o leitor a MARION, 1998, cap. 4.

60 Cf. GOODSTEIN, 1959, p. 20, e GOODSTEIN, 1965, p. 107.

61 Em círculos wittgensteinianos, estas críticas descabidas são muitas vezes confusamente atribuídas à filosofia, já que se considera que a matemática clássica seria uma espécie de bom ponto de partida. Considera-se irrelevante que o "construtivismo" tenha sido desenvolvido por alguns dos maiores matemáticos dos últimos 150 anos, como Kronecker, Poincaré, Borel, Brouwer e Weyl. É como se todos eles estivessem de algum modo contaminados por preocupações filosóficas descabidas. Esta linha de raciocínio é circular, já que pressupõe aquilo que pretende provar (que a matemática está muito bem tal como é). Mas poderíamos ir até mais longe, e dizer que ela só pode ser sustentada por alguém que não sabe do que está falando.

62 Embora Goodstein não cite uma passagem específica de Wittgenstein, é muito provável que ele tivesse em mente RFM,V, $\$ 9$.

63 Isto não é uma observação isolada. Eu a discuto juntamente com outras passagens em MARION, 1998, p. 164-166. Cf. também MARION, 2003.

doispontos, Curitiba, São Carlos, vol. 6, n. 1, p.195-246, abril, 2009 
${ }^{64}$ Eu talvez devesse acrescentar que este ponto de vista é também aquele a partir do qual ele elaborou suas observações a respeito da prova proposta por Euler da infinitude dos números primos, acrescentando uma versão construtiva daquela prova, numa seção do Big Typescript, $\$$ 123 (BT, p. 434-436) (PG, p. 383-386). Para uma análise da mesma, cf. MANCOSU \& MARION, 2003.

65 Cf. CONANT \& DIAMOND, 2004, sec. 5, muito embora obviamente não se vá encontrar ali nenhuma discussão das observações a respeito da matemática.

66 Outra resposta bem mais radical, que é compatível, no entanto, com certos preconceitos que se mantêm há muito tempo, apesar de serem exegeticamente absurdos, seria negar qualquer relevância aos escritos do "período intermediário" e pular diretamente para o outro grande livro, as Investigações Filosóficas. Como é possível que alguém possa achar que a melhor maneira de se compreender um autor seja se recusar conscientemente a ler mais da metade daquilo que ele escreveu? Além de esta postura ser completamente absurda (e, apesar disso, infelizmente surgir com frequência em conversações), ela não explica por que, em 1937, Wittgenstein ainda estava garimpando idéias no Big Typescript, depois que já tinha começado a escrever as Investigações Filosóficas, nas quais há numerosas passagens do Big Typescript - inclusive as malfadadas observações sobre a natureza da filosofia nas Investigações Filosóficas (WITTGENSTEIN, 1953, \$S 90-133), que foram transpostas em sua maioria exatamente como as encontramos em BT, seções 86-93.

67 Estou me referindo, é claro, às Investigações Filosóficas, onde encontramos na seção 254, um equivalente da passagem BT, p. 444, PG, p. 396. Cf. também BT, p. 425, PG, p. 369. Por outro lado, a idéia de que a filosofia "deixa a matemática como ela está” (BT, p. 460) ocorre na seção 124 das Investigações, cujo ancestral direto é, na verdade, um trecho em BT, p. 308.

\section{Referências bibliográficas}

AMBROSE, A. 1935. "Finitism in Mathematics", Mind, n. s., vol. 44, 186-203 \& 317-340.

BROUWER, L. E. J. 1975. Collected Works, 2 vols., Amsterdam: North Holland.

BUNDY, A., JAMNIK, M., FUGARD, A. 2005. "What is a proof?", in Philosophical Transactions of The Royal Society A: Mathematical, Physical and Engineering Sciences, vol. 363, 2377-2392

CONANT, J. 1989.“Must We Show What We Cannot Say ?”, in R. Fleming \& M. Payne (eds.), The Senses of Stanley Cavell, Lewisburg PA: Bucknell University Press, 242-283. 


\section{2}

, 1993. "Kierkegaard, Wittgenstein and Nonsense", in T. Cohen, P. Guyer \& H. Putnam (eds.), Pursuits of Reason, Lubbock TX: Texas Tech University Press, 195-224.

CONANT, J. \& DIAMOND, C. 2004. “On Reading the Tractatus Resolutely", in M. Kölbel \& B. Weiss (eds.), The Lasting Significance of Wittgenstein's Philosophy, London: Routledge, 46-99.

CRARY, A. \& READ, R. 2000. The New Wittgenstein, London: Routledge.

CURRY, H. B. 1941. "A Formalisation of Recursive Arithmetic", American Journal of Mathematics, vol. 63, 263-282.

DIAMOND, C. 1991. The Realistic Spirit, Cambridge MA: MIT Press. , 2000. "Ethics, Imagination and the Tractatus" in CRARY, A. \& READ, R. 2000, 149-173.

FRASCOLLA, P. 1994. Wittgenstein's Philosophy of Mathematics, London: Routledge. 353-378.

,1997. "The Tractatus System of Arithmetic", Synthese, vol. 112,

GOLDFARB, W. 1997. "Metaphysics and Nonsense: On Cora Diamond's The Realistic Spirit", Journal of Philosophical Research, vol. 22, 57-73.

GOODSTEIN, R. L. 1939. "Mathematical systems”, Mind, n. s., vol. 48, 58-73; reprinted in GOODSTEIN 1965, 79-96.

1944. "On the Restricted Ordinal Theorem", Journal of symbolic Logic, vol. 9, 33-41.

,1945. "Function Theory in an Axiom-Free Equation

Calculus", Proceedings of the London Mathematical Society, vol. 48, 401434.

, 1947. "Transfinite Ordinals in Recursive Number Theory", Journal of symbolic Logic, vol. 12, 123-129. 1951. Constructive Formalism, Leicester: Leicester University Press. 
, 1954. "Logic-Free Formalisations of Recursive Arithmetic", Mathematica Scandinavica, vol. 2, 247-261. ,1957a. Recursive Number Theory, Amsterdam, North-Holland. ,1957b. "Critical Notice: Remarks on the Foundations of Mathematics”, Mind, n. s., vol. 66, 549-553. ,1959. The Foundations of Mathematics. An Inaugural Lecture, Leicester: Leicester University Press. (1 ${ }^{\mathrm{a}}$ ed., 1952) ,1961. Recursive Analysis, Amsterdam: North-Holland. 1965. Essays in the Philosophy of Mathematics, Leicester: Leicester University Press. ,1969, "A Constructive Form of the Second Gauss Proof of the Fundamental Theorem of Algebra", in B. Dejon and P. Henrici (eds.), Constructive Aspects of the Fundamental Theorem of Algebra, London: Wiley, 69-76.

, 1972. "Wittgenstein's Philosophy of Mathematics", in A.

Ambrose \& M. Lazerowitz (eds.), Ludwig Wittgenstein. Philosophy and Language, London: Allen \& Unwin, 271-286.

GOODSTEIN, R. L. \& HOOLEY, J. 1960. “On Recursive Transcendence”, Notre Dame Journal of Formal Logic, vol. 1, 127-137. HACKER, P. M. S. 2000. "Was He Trying to Whistle It?”, in CRARY, A. \& READ, R. 2000, 353-388. ,2001. "When the Whistling Had to Stop", in D. Charles \& W. Child (eds.), Wittgensteinian Themes. Essays in Honour of David Pears, Oxford: Clarendon Press, 13-47.

HILBERT, D. \& BERNAYS, P. 1934. Grundlagen der Mathematik, vol. 1, Berlin: Springer.

ISAACSON, D. 1996. "Arithmetical Truth and Hidden Higher-Order Concepts", in W. D. Hart (ed.), The Philosophy of Mathematics, Oxford: Oxford University Press, 203-224. 


\section{4}

KIRBY, L. \& PARIS,J. 1982. “Accessible independence results for Peano arithmetic”, Bulletin London Mathematical Society, 12, 285-93.

KREMER, M. 2002. "Mathematics and Meaning in the Tractatus", Philosophical Investigations, vol. 25, 272-303.

LAMBEK, J. 1988. "On the Unity of Algebra and Logic", in F.

Borceux (ed.), Categorical Algebra and its Applications, Berlin: Springer, 221-229.

LAMBEK J. \& SCOTT, P. 1986. Introduction to Higher-Order Categorical Logic, Cambridge: Cambridge University Press.

MANCOSU, P. \& MARION, M. 2003. “Wittgenstein's

Constructivization of Euler's Proof of the Infinity of Prime Numbers", in F. Stadler (ed.), The Vienna Circle and Logical Empiricism. Vienna Circle Institute Yearbook 10/2002, Dordrecht: Kluwer, 171-189.

MARION, M. 1995a, "Wittgenstein and Finitism", Synthese, vol. 105, 141-176.

,1995b, "Kronecker's 'safe haven of real mathematics"', in M.

Marion \& R. S. Cohen (eds.), Québec Studies in the Philosophy of Science, volume 1, Dordrecht: Kluwer, 187-213.

, 1998. Wittgenstein, Finitism and the Foundations of Mathematics,

Oxford, Clarendon Press.

,2003."Wittgenstein and Brouwer", Synthese, vol. 137, 103-127.

,2008. "Brouwer on Hypotheses and the Middle Wittgenstein", in M. van Atten, P. Boldini, M. Bourdeau \& G. Heinzmann (eds.), One Hundred Years of Intuitionism 1907-2007, Basel: Birkhäuser, 96-114.

MAYBERRY, J. 2000. The Foundations of Mathematics in the Theory of Sets, Cambridge: Cambridge University Press.

MONK, R. 1990. Ludwig Wittgenstein. The Duty of Genius, London: Jonathan Cape.

NELSON, E. 1986. Predicative Arithmetic, Princeton: Princeton University Press. 
OKADA, M. 2007. “On Wittgenstein's Remarks on Recursive Proofs: A Preliminary Report", in M. Okada (ed.), Essays in the Foundations of Logical and Phenomenological Studies, Tokyo: Keio University Press, 121131.

PARIS, J. \& HARRINGTON, L. 1977. “A Mathematical Incompleteness in Peano Arithmetic", in J. Barwise (ed.), Handbook of Mathematical Logic, Amsterdam: North-Holland, 1133-1142.

POTTER, M. 2000. Reason's Nearest Kin, Oxford: Clarendon Press.

PUTNAM, H. 2007. "Wittgenstein and the Real Numbers", in A. Crary (ed.), Wittgenstein and the Moral Life. Essays in Honor of Cora Diamond, Cambridge MA: MIT Press, 235-250.

RAMSEY, F. P. 1923. "Critical Notice: Tractatus Logico-Philosophicus by Ludwig Wittgenstein”, Mind, n. s., vol. 32, 465-478.

ROMAN, L. 1989. "Cartesian Categories with Natural Numbers Object", Journal of Pure and Applied Algebra, vol. 58, 267-278.

ROSE, H. E. 1984. Subrecursion: Functions and Hierarchies, Oxford: Clarendon Press.

ROSE, H. E. 1988. "Obituary: R. L. Goodstein”, Bulletin of the London Mathematical Society, vol. 20, 159-166.

SIMPSON, S. G. 1988. "Partial Realizations of Hilbert's Program”, Journal of Symbolic Logic, vol. 53, 349-363.

SKOLEM,T. 1967. “The Foundations of Elementary Arithmetic established by Means of the Recursive Mode of Thought, without Use of Apparent Variables Ranging over Infinite Domains", in J. van Heijenoort (ed.), From Frege to Gödel. A Sourcebook in Mathematical Logic, 1879-1931, Cambridge MA: Harvard University Press, 303-333.

SMITH, P. 2007. An Introduction to Gödel's Theorems, Cambridge: Cambridge University Press.

SIMPSON, S. G. 1988. "Partial Realizations of Hilbert's Program", Journal of Symbolic Logic', vol. 53, 349-363. 


\section{6}

SULLIVAN, P. 2003. "Ineffability and Nonsense", Proceedings of the Aristotelian Society, Supplementary volume 77, 195-223.

TROELSTRA, A. S. \& van DALEN, D. 1988, Constructivism in Mathematics. An Introduction, volume 1, Amsterdam: North-Holland.

WATSON, A. G. D. 1938. "Mathematics and Its Foundations", Mind, n. s., vol. 47, 440-451.

WITTGENSTEIN, L. 1922. Tractatus Logico-Philosophicus, London:

Routledge \& Kegan Paul. ,1953. Philosophical Investigations, Oxford: Blackwell. , 1974. Philosophical Grammar, Oxford: Blackwell. 1975. Philosophical Remarks, Oxford: Blackwell. 1978. Remarks on the Foundations of Mathematics, 3rd edition, Oxford: Blackwell. ,1979a. Wittgenstein's Lectures, Cambridge 1932-1935, from the notes of A. Ambrose \& M. McDonald, Oxford: Blackwell. ,1979b. Ludwig Wittgenstein and the Vienna Circle, from the notes of F. Waismann, Oxford: Blackwell. , 2005. The Big Typescript. TS 213, Oxford: Blackwell. 